\title{
Approaches to 'place': A study exploring how New Zealand's digital collections conceptualise our social understanding of space
}

by

\section{Flora Feltham}

Submitted to the School of Information Management,

Victoria University of Wellington

in partial fulfilment of the requirements for the degree of

Master of Information Studies 


\section{Abstract}

Research problem: The concept of 'place' has a clear presence in New Zealand's digital heritage collections. However, some theorists suggest there is gap between place as a concept relevant to cultural heritage concerns and place as represented by digital technology. This research explores how geospatial and digital technology deployed in New Zealand's digital collections engage with and conceptualise qualities usually associated with place: social bonds, emotional attachment and subjectivity.

Methodology: This two-stage, mixed-methods study has a qualitative weighting. Web Content analysis (WebCA) gathered data from digital collections that demonstrate placeinclusive features. An anonymous survey gathered opinions from practitioners who create place-inclusive digital collections. Descriptive statistics developed during quantitative analysis triangulated findings developed during thematic qualitative analysis.

Results: New Zealand's digital collections generate a sense-of-place using strategies that mimic subjective and experience-based understanding of the world. Some collections also engage with place in its 'common-sense wrapper' by using the deploying the place in a metadata context or as an overarching thematic structure. New Zealand's cultural heritage practitioners are very practice oriented in their consideration of place, and place-inclusive collections are most often impacted by resourcing issues.

Implications: This project contributes to the growing 'body of sustained critical thinking' focusing on the implications of digital technology for cultural heritage concerns. It suggests place has considerable value and multiple functions within digital heritage collections. When conducting projects using geospatial technology, heritage practitioners can consider supplementing geospatial technology with user-contribution features, content variety, and an emphasis on storytelling to effectively reflect the subjective components of place.

Keywords: digital heritage, geospatial technology, GIS, mapping, place, Web 2.0, 


\section{Acknowledgements}

A very special thank you goes to Dr. Sydney Shep for all her guidance, encouragement and energy over the last year. Her support has been extraordinary and invaluable.

I would also like to thank my classmates and colleagues for providing wonderful company throughout the MIS. I am also grateful for the generous editorial and theoretical insights many of you provided.

Thank you to the organisations actually doing the work that made this project conceivable in the first place; and thank you to the practitioners who contributed their time, thoughts and energy to the survey.

To my family and friends: thank you for the countless ways you have provided support throughout the last year; especially Vicky and Richard. Finally, thank you Pat for your patience, kindness and sense of humour. 


\section{Table of Contents}

$\begin{array}{ll}\text { 1. Introduction } & 7\end{array}$

$\begin{array}{ll}1.1 \text { Background } & 7\end{array}$

1.2 Research Problem 8

$\begin{array}{ll}1.3 \text { Objectives } & 8\end{array}$

1.4 Research Questions 9

1.5 Significance 9

$\begin{array}{ll}1.6 \text { Definitions } & 10\end{array}$

2. Review of the Literature 11

3. Theoretical Framework 20

4. Methodology 22

4.1 Strategy of Inquiry $\quad 22$

4.2 Sample $\quad 22$

4.3 Data Collection $\quad 25$

4.4 Data Analysis $\quad 28$

$\begin{array}{ll}4.5 \text { Validation and Reliability } & 30\end{array}$

4.6 Ethical Considerations 31

$\begin{array}{ll}4.7 \text { Limitations } & 31\end{array}$

5. Results and Discussion 33

5.1 Introduction 33

5.2 Instruments of Place 33

$\begin{array}{ll}5.3 \text { Sense-of-[a particular]-Place } & 37\end{array}$

5.4 The Semantics of Place $\quad 45$

5.5 The Value of Place $\quad 50$

5.6 Place, Geospatial Technology and Web 2.0

5.7 Issues of Place $\quad 56$

6. Conclusion $\quad 59$

7. Works cited 62

$\begin{array}{ll}\text { Appendix 1: Glossary } & 69\end{array}$ 
0091713

Appendix 2: Descriptive codebook $\quad 70$

Appendix 3: Example of survey $\quad 71$

Appendix 4: Example of qualitative analysis 81

Appendix 5: Example of quantitative analysis 82 


\section{Table of Figures}

Figure 1: Stage one sample by project. .p. 24

Figure 2: Stage two sample by organisation type... p.25

Figure 3: Difficulty of factors associated with building place-inclusive digital collections...p.35

Figure 4: Mapping tools or services identified in stage two p.36

Figure 5: Collaborative features identified across stage one and stage two. p.38

Figure 6: Approaches to socialisation and social navigation in stage one p.41

Figure 7: Browse functionality that highlights variety of content format and type p.43

Figure 8: Content formats identified across stage one and stage two p.43

Figure 9: Content types identified across stage one and stage two. .p.44

Figure 10: Approaches to the word place in stage one p. 48

Figure 11: Map-based navigational interfaces in stage one ..p.52

Figure 12: Interactive features that correlate with place-inclusive sites in stage one .p.54

Figure 13: Item record for painting 'Wellington Harbour'. p. 57 


\section{Introduction}

\subsection{Background: The 'spatial turn' in theory}

Following "the recognition that position and context are centrally and inescapably implicated in all constructions of knowledge", 'space' has taken on unprecedented worth in disciplines outside geography (Cosgrove, 1999, p.7). This "spatial turn" (Ethington, 2007, p.465) has engendered new modes of inquiry: concepts like "space, place, scale, landscape, geography, and mapping now permeate...academic and popular cultures as conceptual frameworks, methodologies, and core metaphors" (Daniels, Delyser, Entrikin \& Richardson, 2011, p.ix). This shift also catalysed the "spatial integration of information resources" (Goodchild \& Janelle, 2010, p.3). Within this, the cultural heritage sector increasingly seeks to link resources and content to location (Chen \& Notveitt, 2010; Clough, Tang, Hall, \& Warner, 2011). For example, The Community Archive uses spatial representation as a search method: users can explore the collection via an interactive map of New Zealand (Archives New Zealand, 2013). The CEISMIC Digital Archive, understandably, uses region as a more intangible structural motif: it is "designed to preserve the memories...of the Canterbury region" (CEISMIC, 2013, Homepage). These are just two examples of how the spatial turn manifests in New Zealand's cultural heritage sector.

Foregrounding 'space' and 'place' in cultural heritage practice is seen to offer "a richer, more contextualised understanding of human experience" (Warf, 2009, p.3). Significantly, though, this theoretical approach exists within, and relies on, a digital practice environment (Rumsey, 2009, p.1): institutions must engage with an increasing array of geospatial technologies, processes and Web-based tools to accomplish and deliver geographically-inclusive cultural heritage content or projects. This study, then, contributes to discussion at the intersection of technical and conceptual concerns in cultural heritage after the 'spatial turn'. It explores the concept of place that often underlies geographicallyinflected cultural heritage practice, and how it is understood, conceptualised, generated and shaped by the technical environment available to New Zealand's cultural heritage sector. 


\subsection{Research Problem}

The concept of place has a significant role in motivating and structuring geographicallyinflected cultural heritage practice. Despite this, theorists suggest there is a gap between place as a concept relevant to cultural heritage concerns and place as represented by digital technology: in 2014, geographically-inclusive practices rely on Web-based geospatial data and information management tools but place consists of more than objectified coordinate systems or polygons drawn on a digital map (Crane, 2004; Dwiggins, 2010; Rumsey, 2009; GECO, 2012). This project is motivated by evidence that geospatial technology struggles to reflect "how most people think about the world" and that "cultural heritage information does not include co-ordinates" (GECO, 2012, Humphrey Southall, 2012, para. 2 - 3). How can digital technology capture a sense of place when it is generated through "activities, emotional linkages, social bonds, and other... behaviours that are harder to represent in stasis or concretely" (Rumsey, 2009, p.6)? This project assesses existing digital collections and the experiences of cultural heritage practitioners in New Zealand to understand how place is captured, and the issues that impact its representation.

\subsection{Objectives}

This study aims to:

- identify the practical strategies most commonly associated with successfully conceptualising place using available digital tools and technologies;

- explore how effectively New Zealand cultural heritage institutions' digital collections conceptualise place using these strategies;

- explore where issues arise when conceptualising place within digital collections;

- recommend areas for further investigation, especially in relation to addressing the issues that impact how effectively cultural heritage institutions conceptualise place. 


\subsection{Research questions}

How do New Zealand cultural heritage institutions engage with the concept of place in their Web-based digital collections?

$\bigcirc$ What role is the concept of place seen to have within web-based heritage collections?

- What strategies are commonly employed in New Zealand's web-based collection interfaces to conceptualise place?

- How effective are these strategies at conceptualising place? Are there any clearly identifiable limitations?

- What issues are identified as impacting how cultural heritage institutions conceptualise place in their web-based collection interfaces?

\subsection{Significance}

Providing a rich picture of how New Zealand CHIs engage with place will provide a foundation for shared knowledge. At the broadest level, this project is motivated by the fact that "digital technology has been largely unmapped in terms of a critical theory for cultural heritage" despite its ubiquity (Cameron \& Kenderine, 2007, p.3). By not having a purely technical focus, this project adds to the "body of sustained critical thinking about the meanings and implications of...transformations, challenges and possibilities posed" by digital technology in the cultural heritage sector (Cameron \& Kenedrine, 2007, p.3). This 'body of sustained critical thinking' can transcend individual tools and the lightning-fast pace of technological shifts. More specifically and immediately, this project's results identify shared issues and where organisations may or may not need guidance in their practices as they seek to engage meaningfully with geospatial technology; and seek to provide spaces for their users to engage meaningfully with digital content. This combination of theory and practice brings us closer bring us closer to developing a comprehensive, evidence-based body of research upon which institutions can produce high-quality geographically-inclusive cultural heritage projects in New Zealand. 


\subsection{Definitions}

Digital collection: an online space, accessed through a Web-browser, where users engage and interact with digital heritage content e.g. website, online exhibition (Ruecker, Radzikowska \& Sinclair, 2011, p.3 - 4).

Cultural heritage institution (CHI): organisation with a mandate to "educate and elucidate, to promote and disseminate and to preserve culture" (Deegan \& Tanner, 2006, p.1).

Geographic information: refers to any phenomena or object "that exists in Earth space [and] can be mapped onto a representation of the globe" (Rumsey, 2009, p.2) e.g. geospatial data (co-ordinate systems, projections), maps or location images.

Place: peoples' subjective, social understanding of location; distinguished from the mathematical understanding of measureable, physical 'space' (Tuan, 1977; Jordan, Raubal, Gartrell \& Egenhofer, 1998, p.3 -4). place is "space infused with human meaning" generated through experience, emotional linkages and social bonds (Jordan, Raubal, Gartrell \& Egenhofer, 1998, p.2; Rumsey, 2009, p.6).

Place-inclusive digital collection: "web-sites and digital projects which recognise human identity with an attachment to place, and convey a 'sense of place' to viewers through diverse web-based techniques and environments" (Von Seggern, Merrill \& Zhu, 2010, p.274).

The 'spatial turn': a cross-disciplinary "exploration of space and place...supported by technologies that represent spatial...dimensions" permitting users to "discover, analyse, represent, and argue various interpretations of spatial data" (Rumsey, 2009, p.1). 


\section{Review of the Literature}

\section{The 'spatial turn' in practice: The rise of Web-mapping}

The 'spatial turn' is a cross-disciplinary, intellectual shift which asserts that "the geographic dimension...[is] an essential aspect of the production of culture" (Warf, 2009, p.1). Theoretically, this approach is characterised by an:

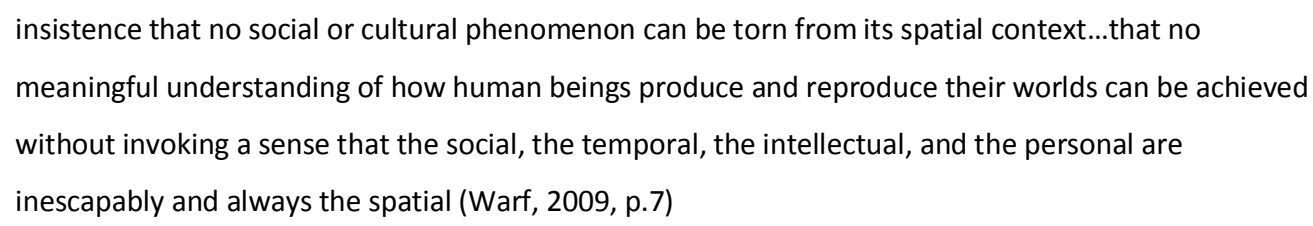

In practice, the 'spatial turn' is characterised by a digital environment saturated with tools that support spatially-inclusive inquiry and practice (Rumsey, 2009, p.1). This is because spatially-inclusive approaches to intellectual exploration require, alongside other familiar research tools, specialised geographic information systems (GIS) to "structure, integrate, manipulate, analyse and display" geospatial information like co-ordinates, attribute data or maps (Gregory \& Ell, 2007, p.1).

In 2014, the Web often provides this environment for conducting and delivering geographically-inclusive projects: it has emerged as the gateway for using, disseminating and visualising geospatial information (Florance, 2006, p.223; Goodchild \& Janelle, 2010, p.5; Rumsey, 2009, p.1). Currently, the suite of Web-based practices surrounding geospatial information is known as "Web-mapping" (Morris, 2006, p.285). Overwhelmingly, the most common general-purpose tool is Google Maps and its accompanying API (Dodsworth \& Nicholson, 2012, p.107; Goodchild \& Janelle, 2010, p.5; Geospatial Engagement and Community Outreach [GECO], 2012, Stuart Nicol, para.4). From a cultural heritage perspective, the current web mapping these tools "are far more accessible than traditional GIS...and make it possible for smaller, less technical institutions to take advantage of Webbased mapping" (Dwiggins, 2010, para.25 ).

\section{What does 'geographically-inflected cultural heritage practice' look like?}

The above phrase is deliberately inclusive and refers to the process of foregrounding the 'geographic dimension' within otherwise familiar cultural heritage practices. Empirically, it 
covers a variety of activities that - while they have disparate aims - can all be grouped under one banner: using geospatial information and/or technology to associate and deliver heritage resources, content and collections in a context of location (Chen \& Notveitt, 2010, p.159; Hall \& Warner, 2010). This section outlines the three most commonly identified forms of geographically-inflected cultural heritage practice and associated technologies, processes, motivations and issues.

\section{a. Using geospatial information for meaningful collection discovery}

In a cultural heritage environment, geospatial information is used to support collection discovery by providing visual metadata and navigational context (Morris, 2006, p.292). Most commonly, digital collections use the Google Maps API to embed an application that visualises an item's geospatial component through a point on a map (Dodsworth \& Nicholson, 2012, p. 104). This practice seems to reflect beliefs about the nature of users and heritage content. Firstly, "[g]eography provides an important facet for information seeking" because this reflects how people categorise the world (Clough, Tang, Hall and Warner, 2011, p.128): "[p]lace...is one of the fundamental components in how we define things and search for them" (Buckland \& Lancaster, para.27). Geospatial information is also seen to accurately render the nature of cultural heritage content because resources virtually always have a link to place (Dwiggins, 2010, para.5) through "geographical identifiers, including place names (or toponyms) [and] addresses" (Clough, Hall and Warner, 2011, p.127). This applies at the series or collection level since many institutions "thematically group content...on geographical origin" (Harkema \& Nygren, 2012, para. 4). Most significantly, geospatial information provides a transcendental lens for aggregating material across institutions: "place allows...seamless access across heterogeneous" collections (Clough, Tang, Hall and Warner, 2011, p.128) and allows us "to build an open ecosystem of historical data across libraries, archives and museums" (Voss, 2012).

However, there are some limitations to the utility of using geospatial information for collection discovery. Some commentators "disabuse the notion that spatial thinking is 'intuitive'" (Rumsey, 2009, pg.4) while others take issue with the 'inherent' applicability of geospatial tools to all heritage material. While a postcard collection plays to Historypin's strengths not all archival material is the same: "effective collections need to be visual...and 
images should contain a perspective that adapts well to Google Street View (Harkema \& Nygren, 2012, para.18). Furthermore, visual metadata and interfaces are "almost entirely impenetrable to search engines" (GECO, 2012, Southall, para. 2) so, "as a method of discovering collections" can lose value (Harkema \& Nygren, 2012, para.22).

\section{b. Using geospatial information for supporting scholarship}

Many cultural heritage organisations facilitate access to geospatial information as a research resource (Knowles, 2008, p.6; Morris, 2006, p.286; Southall \& Pridal, 2012, p.74). This reflects more traditional 'map library' concerns, where maintaining a collection of geographic content is the core focus (Morris, 2006, p.290). ECAl provides an array of "georeferenced resources" to encourage scholarship focused on place (Buckland \& Lancaster, 2004, para 2). A more conspicuous trend is towards using geospatial applications as methodological tools for analysis or communicating findings (Goodchild \& Janelle, 2010, p.5). Many cultural heritage projects deliver and visualise content in its geographic context with the aim of stimulating scholarly inquiry: "research questions are generated when spatial relationships are modelled" (Harkema \& Nygren, 2012, para.11; Rumsey, 2009, pg.3). Geospatial "visualisations and interfaces allow for different types of analysis not readily available in traditional digital library interfaces" (Harkema \& Nygren, 2012, para.11).

Geospatial information is "pivotal for interdisciplinary inquiry" (Buckland \&Lancaster, 2004, para.28) because it provides a collective lens for interpretation (Rumsey, 2010, p.3). Apparently, "botanists, civil engineers, economists, epidemiologists, geologists, historians....are all more or less interested in space and place [so] it is...effective to bring together everything associated with a particular place" (Buckland \& Lancaster, 2004, para. 27). For some, however, the quality of scholarship is threatened by an increase of "intermediate resources that provide compendia of primary sources or partially digested digitally organised information" (Knowles, 2008, p.6). Visualisation on the web "leaves the final synthesis to the reader": a map can only ever present the constituent parts of an argument, never an integrated whole (Knowles, 2008, p.6). More pertinently, the involvement of para-scholarly organisations stops scholars engaging directly with material: "making historical materials more conveniently available saves researchers time....but if one 
does not grapple with raw data, can one know a source well enough to use it creatively?" (Knowles, 2008, p.6).

\section{c. Using geospatial information for building community}

Many organisations use geospatial information as a platform for community engagement (Harkema \& Nygren, 2012, para.15): Historypin's explicit purpose is “building community around history" (Voss, 2012). Used to catalyse "collaboration and participation", geospatial information sits within the sphere of Web 2.0 practices (Dwiggins, 2010, para.20). An emphasis on "user-created content" is the most familiar characteristic to these ends: mapbased applications often offer "special functions for user contributions" (Chen \& Nottviett, 2010, p.160). More significantly, geospatial information forms a central component of "mash-up" culture, whereby users do not just add content, they take "content and [do] other things with it as a way to provide new perspectives" (Voss, 2012). Geospatial information is a particularly powerful catalyst for mash-ups because it is interoperable with many easy-to-use visualisation or dissemination tools like Google Earth (Dwiggins, 2010, para.20; Rumsey, 2009, pg.4; Bray, 2012). Since APIs are "largely responsible for the growing popularity of mash-ups" (Scharl, 2007, p.5) many organisations now provide "open interfaces that enable the creative combinations...of data" (Dwiggins, 2010, para.20): they capture item information like longitude/latitude and expose that to the Web environment (Morris, 2006, p.296; Bray, 2012).

Geospatial information is effective for building community because it can appeals to and reaffirms how people understand the past (Goodchild \& Janelle, 2010, p.7; Von Seggern, Merrill \& Zhu, 2010, p.274). For communities and individuals, "[h]istorical consciousness and place consciousness are inextricably intertwined. We attach histories to places" (Glassberg, 1996, as cited by Dwiggins, 2010, para. 4; Voss, 2012). So, by endorsing place, heritage institutions enact their mandate in way consistent with how their communities engage with the past: providing "communities with the raw materials to support collective memory and create an effective 'sense of place'...requires exposing the underlying geographical locations...documented by archival records" (Dwiggins, 2010, Para. 1). 


\section{The implicit foundation in place}

In this rough typology of geographically-inflected cultural heritage practice, one distinctive thread stands out: the ubiquitous presence of place. Place functions semantically as a subject heading or indexing term (Edwardes \& Purves, 2007b, p.106). It functions thematically as a collection aggregator (Voss, 2012). It functions conceptually as a navigational lens (Dodsworth \& Nicholson, 2012, p.104; Harkema \& Nygren, 2012, para.11). Indeed, place is seen to have "near universal relevance" (Goodchild \& Janelle, 2010, p.6) because it reflects how people categorise the world (Clough, Tang, Hall \& Warner, 2011, p.127), how communities comprehend history (Dwiggins, 2010; Von Seggern, Merill \& Zhu, 2010, p.274) and how scholars understand their disciplines (Buckland \&Lancaster, 2004; Rumsey, 2010). The 'spatial turn', as it manifests within the cultural heritage sector, relies on an inherent link between cultural heritage and place: "[a]rchives play a key role in the creation and maintenance of a sense of place" (Dwiggins, 2010, para. 2). An appeal to place is often used as the structural or motivating concept behind a variety of digital heritage collections; despite these projects addressing significantly different heritage concerns and achieving different goals.

\section{But what exactly is place?}

Academically, the study of place is a component of human geography (Cresswell, 2004, p.1; Withers, 2009, p.640). The concept is also notably malleable and inexact (Withers, 2004, p.638):

no-one quite knows what they are talking about when they are talking about place. Place is not a specialized piece of academic terminology... It is a word wrapped in common sense. In one sense this makes is easier to grasp. In another sense... this makes it more slippery (Cresswell, 2004, p.1)

Place has multiple definitions, dimensions and properties that can change, or even conflict, depending on the context of its use (Withers, 2004, p.639). The simplest definition of place is as "a meaningful location" (Cresswell, 2004, p.7). Yi-Fu Tuan famously defines place in opposition to 'space' (Withers, 2009, p.638; Tuan, 1977): “what begins as undifferentiated space becomes place as we get to know it and endow it with value" (Tuan, 1977, p.6). Arguing from a phenomenological standpoint, Edward Relph states that places are 
"significant centres of our immediate experiences of the world" (Relph, 1976, p.141): place is an elemental component of human consciousness (Seamon \& Sowers, 2008, p.45). For both Tuan and Relph, recognising place is an epistemological stance - a way of relating to the world - that resists the nomothetic impulse of 'spatial science' (Cresswell, 2004, p.20; Cresswell, 2008, p.54). Seeing the world as a series of places like 'home' or 'my neighbourhood' challenges a view of the world as gird of co-ordinates (Cresswell, 2004, p.11); not least because places are created through our direct experience, emotional responses, un-examined consciousness and subjective perception (Seamon \& Sowers, 2008, p.44; ).

Other theorists disagree that place is an essential, authentic aspect of human existence or consciousness. David Harvey argues that place is a "social construct", and we should only ask one question: "by what social process(es) is place constructed?" (Harvey,1996, as cited by Cresswell, 2004, p.29). For Harvey, places are "constructed" to reflect the power relations of global capitalism (Cresswell, 2004, 50). Doreen Massey, though, argues against Harvey's anxiety surrounding constructed place. She states that in an era of globalisation places are an "inclusive and progressive site of global life" (Cresswell, 2004, p.63).

Regardless of arguments about the derivation of place, CHIs predominantly conceive of and engage with place as an intangible phenomenon. They aim "to document...place in society" (Goodchild \& Janelle, 2010, p.5), or catalyse "connections between content, history, and... 'sense of place'"' (Harkema \& Nygren, 2012, para.15). place, for CHIs, is definitively linked to human understanding, not a scientific lens.

\section{Limitations of geospatial technology}

Unfortunately, accessing this "social world is tougher" for geospatial technology (Rumsey, 2009, p.6). Despite some assertions that geocoded resources are "keys to...place-based knowledge" (Goodchild \& Janelle, 2010, p.7) and "latitude and longitude constitute a lingua franca" for specifying place (Buckland, \& Lancester, 2004, para.28), theorists concede that "place encompasses more than just recorded" phenomena (Dwiggins, 2010, para.2). Significantly, "places are created by direct experience and sensation" (Edwardes \& Purves, 2007a, p.15). But these "activities, emotional linkages [and] social bonds" (Rumsey, 2010, p.6) are extremely hard to capture and transmit with digital processing since geospatial 
technology only “models space with reference to...coordinates (Jordan, Raubal, Gartrell \& Egenhofer, 1998, p.3 -4). That is, Gecoding only links heritage content to "objectified coordinate systems" but not lived, subjective experience (Crane, 2004, para.3). It is only when "spaces defined by mathematics and physics are [imbued] with human experience" that they become 'places' (Jordan, Raubal, Gartrell \& Egenhofer, 1998, p.4).

\section{Conceptualising place using geospatial tools}

Some theorists postulate strategies for conceptualising place using digital tools. These can be characterised as strategies for shifting from "the universal and objective to the more individual and subjective" (Edwardes \& Purves, 2007b, p.106). Emphasizing visual representation of content in a collection interface is one recommended strategy: images, photography and film are seen to reflect place strongly because they have an inherent "sense of location" (GECO, 2012, Humphrey Southall, para. 2; Fisher \& Unwin, 2005, as cited by Edwardes \& Purves, 2007b, p.107). More ambitiously, place-inclusive interfaces should seamlessly deliver "a mix of resource types such as text, visual, audio and geospatial" to "establish unique character and a distinctive identity for a place" (Von Seggern, Merrill \& Zhu, 2010, p.281; Farrelly, 2013, Conclusion). Furthermore, storytelling is seen as a powerful strategy for augmenting map-based representation because stories are consistent with the "textual" understanding people have of place (GECO, 2012, Humphrey Southall, para.2).

Allowing users to personalise collection content is also seen to generate 'a sense of place': "[t]he capability of adding user-generated content, whether it is original...or additions to supplied digital objects...promotes a 'sense of place"” because it "captures the personal experience" (Von Seggern, Merrill\& Zhu, 2010, p.277). Finally, the most comprehensive account of place to date is provided by Glen Farrelly, who offers a set of six design heuristics that meet the "place-related needs of users" (2013, Conclusion) in location-based services (LBS). Mobile apps should "allow personal experience to be recorded privately and publicly; offer personalization features; consider affect; draw upon various information source types; offer different types of information; [and] ensure content is available across many locations". While these are aimed specifically at LBS, many of them also apply to information sources like digital collections. 


\section{The local perspective}

In New Zealand, many national and regional CHIs perform geographically-inflected cultural heritage practices that mirror the internationally identified trends. Many $\mathrm{CHIs}$ provide spatially-enabled searching and navigation. The Upper Hutt City library's “Recollect Heritage Collections" is supported by user-added geotagging and allows users to browse the collection via a map interface (Upper Hutt City Library, 2014, Home). The Community Archive also encourages users to "explore collections" by place using a Google Map index (Archives New Zealand, 2009, Home). Archives New Zealand and Te Papa both have Historypin channels that provide collection searching and content delivery. The $28^{\text {th }}$ Māori Battalion site is an example of using geospatial information for more scholarly or educational purposes. The digital history site uses an interactive map to provide access to user-contributed stories and well as educational resources (Ministry for Culture and Heritage, n.d., About this Site). Interestingly, while this site engages many of the strategies for generating place, it does not explicitly reference the concept. CEISMIC, conversely, has less engagement with geospatial technology like interactive maps, but is a strong example of a digital collection with an explicit link to place. It is a large-scale, project drawing from many cultural heritage organisations and is dedicated to remembering the Christchurch earthquake: CEISMIC casts "a net over our cultural heritage community to give the people of Christchurch and New Zealand a single place to create, remember and research their heritage" (CEISMIC Consortium, 2014, Home). In New Zealand, it is clear that many organisations conduct geographically-inflected cultural heritage practices; what remains unclear is the role place has in these practices and how it is understood and generated.

\section{Summary}

The 'spatial turn' has seen cultural heritage institutions increasingly engage with geospatial technologies to foster meaningful collection discovery and navigation, to support scholarship, to build community and to tell stories. One concept that frequently motivates these geographically-inflected cultural heritage practices is place: peoples' subjective and socially-produced understanding of space. Despite the fact that place is perceived as relevant to an array of cultural heritage concerns, theorists and practitioners also concede that available geospatial technology struggles to generate or capture a genuine sense of 
place. Many strategies are suggested as ways around this disconnect. These include foregrounding visual or multimedia representations, demonstrating change over time through storytelling, allowing users to personalise a digital space and connect with other users. In New Zealand, there are a number of geographically-inflected collections which may also employ these strategies for articulating place. 


\section{Theoretical Framework}

The newness of this topic meant that no single, unified theoretical model was appropriate for understanding and evaluating how digital collections engage with the concept of place. To address this, the following approaches to theory were used. Firstly, in the absence of a strict theoretical context, the researcher followed an inductive strategy suggested by Bryman and used the existing body of literature as an equivalent, alternative form of guidance (2012, p.23). A prevailing qualitative methodology in the field means the literature is predominantly idiographic: based on descriptions of institutions' unique experience (e.g. Chen \& Notviett, 2010; Harkema \& Nygren, 2012; Bray, 2012). The common uses, strategies and issues related to conceptualising place identified across these studies provided a guide for recognising the same variables in New Zealand. Emergent patterns and themes were further identified through content analysis of digital collections in the first stage of the study and enriched by triangulating data against practitioners' experiences in the second.

Secondly, in order to discuss the concept of place as a social phenomenon infused with human meaning that may be separate from purely spatial representation (Jordan, Raubal, Gartrell \& Egenhofre, 1998, p.99), this project followed Dwiggins (2010) and Harkema \& Nygren (2012) who evoked John Agnew's three tier typology to distinguish between "three fundamental aspects of place": location, locale, and "sense of place" (Withers, 2009, p.639). Place as location is "the grid references we attach to portions of the earth's surface by... latitudinal and longitudinal positioning". Place as locale is the "material setting for social relations". Lastly, place as sense-of-place "is taken to embrace the affective attachment that people have to place" (Withers, 2009, p.640). This will allow the researcher to discuss different components of place, as well as conceptual and technical matters, separately.

To discuss conceptual issues like the derivation or properties of place, and sense-of-place, this project drew from three noteworthy place theorists: Yi-Fu Tuan (1976), Edward Relph (1977), and Doreen Massey (1994). Theory surveys by Timothy Cresswell (2004) and Charles Withers (2009) were used to enhance an understanding of all three. These theorists were 
chosen because they represent key perspectives on the nature of place. While no samples declared their theoretical stance, the researcher could use these theories to interpret which of these perspectives on place may be demonstrated in New Zealand's digital collections. 


\section{Methodology}

\subsection{Strategy of inquiry}

This project is a two-stage, mixed-methods study with a strongly qualitative weighting. The qualitative weighting and an emergent approach reflect the unknown nature of the topic: providing a rich picture of how digital collections engage with place relies on a dispersed, partial theory-base and as yet unknown variables (Creswell, 2009, p.18; Leedy \& Ormrod, 2012 , p.139). Generally, data analysis relied on interpretation and inductive reasoning which follows naturally from the qualitative weighting (Leedy \& Ormrod, 2012, p.139). In addition to qualitative data, both stages generated some quantitative data, and both varieties were triangulated during a final analysis. This mixed-methods strategy was the most effective way to "develop a detailed view of the meaning of a phenomenon or concept" (Creswell, 2009, p.18).

\subsection{Sample}

This project draws from the population of cultural heritage institutions that engage with the concept of place in their digital collections. Since a pre-defined list of this population did not exist, the sampling was guided by the "needs of the study" (Boeije, 2010, p.35). Consequently, two sampling strategies were used to ensure examples and participants were "selected because they have experienced the central phenomenon" (Creswell, 2009, p.217).

\section{Stage One}

In stage one, the unit of analysis was individual digital collections that demonstrate placeinclusive thinking, practices and features. A strategic, purposive sampling method was used because it allowed the researcher to ensure "those sampled are relevant to the research questions" (Bryman, 2008, p.415). LIANZA's Public Library Statistics 2011/2012 (LIANZA, 2012), the NZMuseums directory (National Services Te Paerangi, n.d.) and The Community Archive directory (Archives New Zealand, 2009) were used to identify a range of organisations engaged in cultural heritage practices but also efficiently exclude those unlikely to be engaged with cultural heritage at all e.g. corporate libraries. The directories were collated into a list of $676 \mathrm{CHIs}$ reflecting a variety of organisations: art galleries, large 
or small archival repositories, museums, and libraries with special collections. Due to time constraints, the digital collections associated with only 178 of these $\mathrm{CHIs}$ were able to be assessed. A collection could be selected for inclusion in this project if it met any of the following criteria indicating engagement with place:

1. it used embedded geospatial technology within main collection website OR thirdparty geospatial technology separate from main collection website to support the delivery of digital heritage content

2. it used the word place or places as a theme for organising digital heritage content

3. it used a particular identifiable place as the single theme for organising digital heritage content

These criteria were developed from a list of the features associated with place-inclusive digital collections described in the international literature. These include deliberate guidelines on the features and content necessary for place-inclusive sites (Farrelly, 2013; Merrill, Von Seggern \& Zhu, 2010), and those characteristics of digital collections associated with place as they were written up in case-studies (Chen \& Notviett, 2010; Clough, Tang, Hall and Warner, 2011; Dwiggins, 2010; Harkema \& Nygren, 2012).

Ten digital collections that met sampling criteria were selected for inclusion in stage one (Figure 1). The main aim was to select digital collections that reflect the spectrum of possible place-inclusive features and to capture the array of digital environments and techniques that leverage place. Secondly, the ten collections were selected because they are demographically and functionally diverse: they range in scale and geographic focus; they come from pan-organisational and intra-organisational teams and represent a variety of heritage interests (e.g. were either predominantly library-focused or museum focused). Thirdly, the digital collections reflect a variety of ways to engage with digital heritage content: some collections use formal, traditional IRS (e.g. Te Papa), and others use innovative and untraditional IRS (e.g. The Bulldog \& the Battlecruiser). Finally, the collections were chosen because they were would allow the researcher to answer an array of research questions and isolate a variety variables (e.g. is GIS alone if a sufficient condition for conceptualising place?). Essentially, the small sample size and considerable variety 
reflects the need to efficiently generate rich data about an unknown topic within a limited time frame (Creswell, 2009, p.227).

Figure 1: Stage one sample

\begin{tabular}{|c|c|c|c|c|}
\hline Digital collection & $\begin{array}{l}\text { Represent } \\
\text { one place }\end{array}$ & $\begin{array}{l}\text { Word place/s } \\
\text { as a theme }\end{array}$ & $\begin{array}{l}\text { Geospatial } \\
\text { technology }\end{array}$ & URL \\
\hline The Prow & Yes & Yes & Yes & http://www.theprow.org.nz/ \\
\hline $\begin{array}{l}\text { Upper Hutt } \\
\text { Recollect }\end{array}$ & Yes & Yes & Yes & http://uhcl.recollect.co.nz/ \\
\hline $\begin{array}{l}\text { [Te Papa] } \\
\text { Collections Online }\end{array}$ & No & Yes & Yes & $\begin{array}{l}\text { http://collections.tepapa.govt.nz/ } \\
\text { search.aspx }\end{array}$ \\
\hline $\begin{array}{l}\text { 28th Māori } \\
\text { Battalion }\end{array}$ & No & No & Yes & $\begin{array}{l}\text { http://www.28Māoribattalion.org } \\
. \mathrm{nz} /\end{array}$ \\
\hline $\begin{array}{l}\text { [Christchurch Art } \\
\text { Gallery] Collection } \\
\text { Online }\end{array}$ & No & No & Yes & $\begin{array}{l}\text { http://christchurchartgallery.org. } \\
\underline{\text { nz/collection/ }}\end{array}$ \\
\hline $\begin{array}{l}\text { The Bulldog and the } \\
\text { Battlecruiser }\end{array}$ & No & No & Yes & $\frac{\text { http://www.hmsnewzealand.com }}{\text { /page/about }}$ \\
\hline $\begin{array}{l}\text { Auckland City } \\
\text { Libraries, Heritage } \\
\text { and Research } \\
\text { Historypin Channel }\end{array}$ & Yes & No & Yes & $\begin{array}{l}\text { http://www.historypin.com/chan } \\
\text { nels/view/33636/\#!photos/list/ }\end{array}$ \\
\hline Quakestories & Yes & No & Yes & http://www.quakestories.govt.nz/ \\
\hline $\begin{array}{l}\text { [Akaroa Museum] } \\
\text { Collections }\end{array}$ & Yes & No & No & $\begin{array}{l}\text { http://www.akaroamuseum.org.n } \\
\text { z/collections.asp }\end{array}$ \\
\hline $\begin{array}{l}\text { Central Hawke's } \\
\text { Bay Kete }\end{array}$ & Yes & Yes & No & $\begin{array}{l}\text { http://ketechb.peoplesnetworknz } \\
\text { info/ }\end{array}$ \\
\hline
\end{tabular}

\section{Stage Two}

In stage two, the unit of analysis was the reported experiences and opinions of organisations that create place-inclusive digital collections. Following a strategy suggested by Bryman (2008, p.652), a succinct email was sent to the NZ-Libs listserv and the NZ Records listserv to invite participation in an anonymous web survey from participants who had experience creating or contributing to digital collections that met the sampling criteria. The email included a detailed description of the sampling criteria, informed consent information and provided a link to a web survey (Appendix 3). The aim was a sample size of 60 to effectively augment the conclusions drawn from the stage one data.

The survey response rate was just over $50 \%$. Responses were returned from practitioners working at organisations of every type offered as an option (Figure 2). The designation 
"Other" included "personal collection", "Secondary school" and "Association". This sample indicates that a variety of New Zealand's CHIs engage with the concept of place. The fact that the two largest respondent groups identified as research libraries (30\%) and archives (26\%) indicates New Zealand is consistent with international trends. In literature, the organisations most frequently engaged with place-inclusive activities are digital and academic libraries (Chen \& Notviett, 2010; Harkema \& Nygren, 2012), and archives (Clough, Tang, Hall and Warner, 2011; Dwiggins, 2010). No respondents further specified library type, so it is not possible to separate results into findings relative to digital libraries versus non-digital libraries.

\section{Figure 2: Stage two sample}

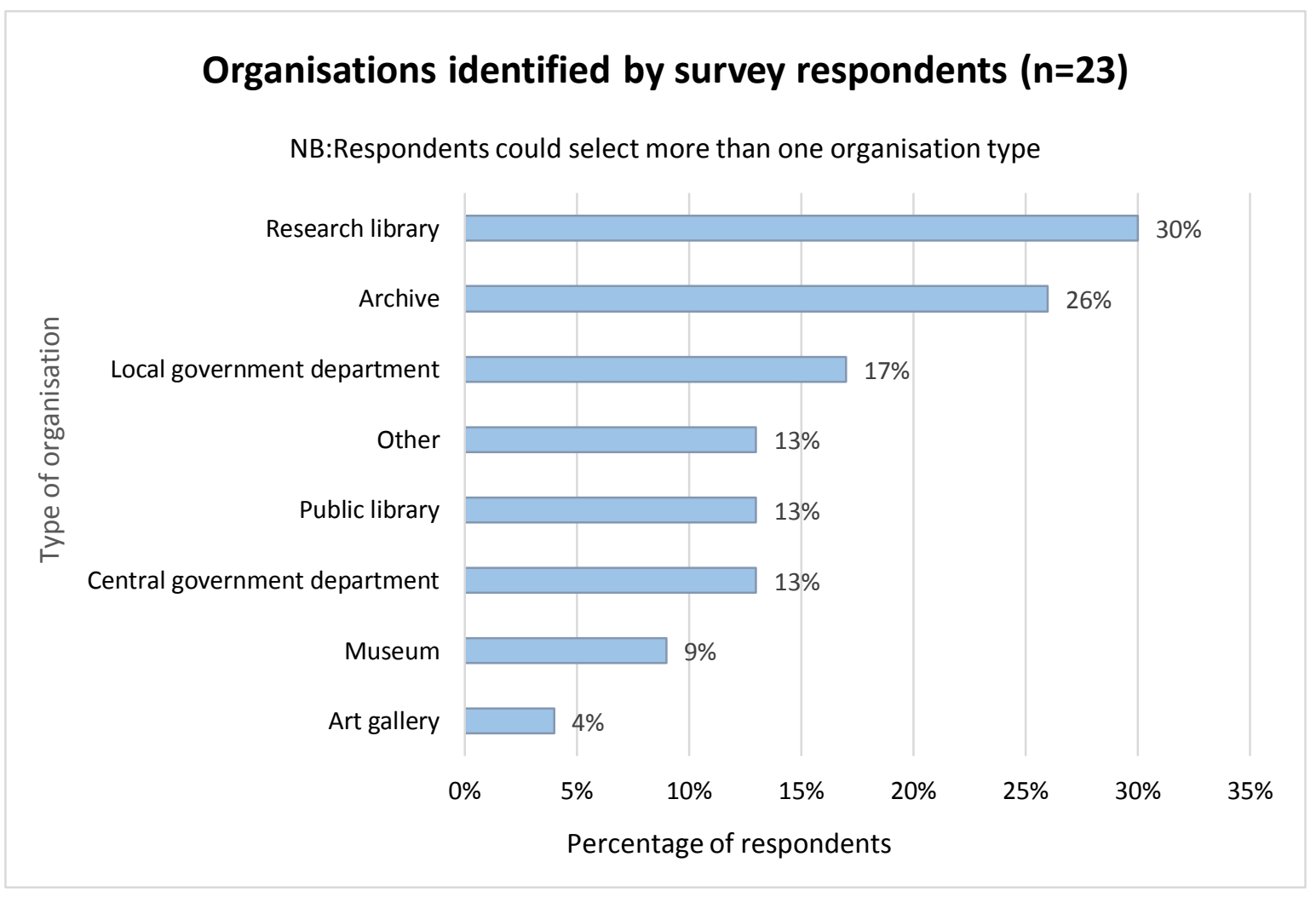

\subsection{Data Collection}

\section{Stage One: Content Analysis}

Content analysis is suggested as a strategy for evaluating place-inclusive digital collections by Von Seggern, Merrill \& Zhu (2010). It has also been chosen for its flexibility and capacity 
for generating rich data from raw materials: content analysis can be applied to mixed-media or visual material; and can capture both objective, quantitative data (e.g. frequency) and interpretive, qualitative data (e.g. themes) (Bryman, 2008, p.275; Leedy \& Ormrod, 2012, p.149). This project's general approach to content analysis follows Berg (2009, p.338 - 366) and Saldaña (2009). Regarding Web content analysis specifically the project was guided by Herring (2010) and Weare \& Lin (2000). It followed Herring's model of "an expanded Web Content Analysis (WebCA) paradigm in which insights from other paradigms are operationalized and implemented within a general CA framework" (Herring, 2010, p.234). This "methodological innovation" addresses the way that the Web challenges the effectiveness of traditional content analysis techniques (Herring, 2010, p.234). By following Herring, the researcher was able to collect data usually captured as part of usability inspections, IRS evaluation or $\mathrm{HCl}$ interface evaluation and operationalize it within the scope of this study.

While Von Seggern, Merrill \& Zhu (2010) suggest an entire website is an appropriate unit of analysis, this is considered too inexact by Herring (2010), Weare \& Lin (2000). Researchers concede that the Web's "multimodality poses challenges to content analysis, especially as regards the identification of units of analysis" (Herring, 2010, p.2348) so "researchers are forced to take greater care in the definition of units of analysis" (Weare \& Lin, 2000, p.280). This project used a functional definition to stipulate the unit of analysis: it was the sections of the digital collection where users engage with heritage content. As a quantifiable rule of thumb, the following parts of each collection were coded: the collections landing page; the IRS features; and item or content records. Supporting documentation like an 'About this Site' page and source code was used to identify and clarify features or site functionality which was potentially unclear.

Coding categories were determined by both inductive and deductive methods since a dual approach allows for rich data collection (Berg, 2009, p.347). In the "deductive approach, researchers use some categorical scheme suggested by a theoretical perspective" to guide coding (Berg, 2009, p.347). Accordingly, higher-level concept categories and some discrete codes were derived from Farrelly (2013) and Von Seggern, Merrill \& Zhu (2010) who provide overt guidance on the kinds of functionality, features and content used by place-inclusive 
sites. Following Saldaña (2009, p.2 - 30) and Berg (2009), inductive codes and categories were developed through 'immersion in the documents' and extensive open coding "to identify the dimensions...that seem meaningful to the producers" (Berg, 2009, p.347). Accordingly, each digital collection was assessed for any recurring observable components not captured by deductive categories. For example, new codes were developed around copyright or creative commons re-use of material within each digital collection. Attribute codes captured basic descriptive information about each sample (e.g. project type, contributing CHIs) and were used to manage data and provide "consistency and comparison" across the sample during later analysis (e.g. CHI type) (Saldaña, 2009, p.56). Descriptive coding was used to capture the "data's contents" (e.g. topics apparent in written content on collection landing page; structural features of IRS) so analytic codes could be applied during later coding cycles (Saldaña, 2009, p.72). Following first-cycle deductive and inductive coding, all stage one data was collated into a descriptive codebook (Saldaña, 2009, p.72) (Appendix 2). Saturation was used to ensure that no new codes were emerging (Creswell, 2014, p.201)

\section{Stage Two: Survey}

Stage two data was collected through an anonymous web survey administered online through Qualtrics software (Appendix 3). An emergent strategy meant that survey questions were guided by themes identified in the literature and emergent findings from stage one. Questions designed to gather attribute data were guided by the types of organisations reporting place-inclusive activities in the international literature. While these did not seem to include many local or government departments, many stage one collections were maintained (in part) by central or local government departments. These options were subsequently included in the relevant survey question as they were clearly relevant to the New Zealand context. Questions regarding the features, tools, information formats and content types associated with place-inclusive digital collections were derived the high-level categories outlined in Von Seggern, Merrill \& Zhu (2010), and Farrelly (2013); the specific tools mentioned in international case studies; those tools apparent from stage one content analysis. 
A pilot survey was evaluated for clarity, validity and effectiveness by three testers. The aim was to update and strengthen the survey based on the understanding of i) those with relevant broad, professional knowledge (a PhD student in the School of Information Management); ii) those intended participants with expert knowledge (a practitioner working with digital heritage content at Victoria University of Wellington); and iii) the wider public (a layperson). The survey was administered for four weeks between 16 December 2013 and 14 January 2014. To encourage a bigger response rate, a reminder notice about the survey was sent out on 08 January 2014. Lastly, a survey also allows for standardised data collection: if all respondents answer the same questions, inferences can be drawn across the whole sample (Leedy \& Ormrod, 2012, p.92).

\subsection{Data Analysis}

\section{Overview}

This project's approach to data analysis uses a "parallel convergent design" whereby the "researcher collects both quantitative and qualitative data, analyses them separately, and then compares the results" (Creswell, 2014, p.219). The project also includes an exploratory component since emergent stage one findings informed stage two data collection. However, a formal "exploratory, sequential" approach was unsuitable because of the complicating factor that both stages generated qualitative and quantitative data (Creswell, 2014, p.225). Therefore, to engender systematic analysis, data types from both stages were treated separately, and then brought together during triangulation. Microsoft Excel stored the descriptive codebook as it was developed during stage one data collection; this software also stored subsequent analytical matrices, and all triangulated data. Qualtrics was used to store and tabulate quantitative data gathered in stage two.

\section{Qualitative approaches}

Importantly, "analysis in qualitative research will proceed hand-in-hand with other parts of developing the qualitative study, namely the data collection" (Creswell, 2014, p.195): stringently delineating qualitative WebCA data collection from qualitative WebCA data analysis is problematic. However, since the codebook developed during stage one was 
predominantly descriptive, analysis can be said to have started at the end of stage two data collection, after the application of descriptive codes to survey long-answers, and the collation of all qualitative data. A framework-based approach to thematic analysis was used to develop qualitative findings: the researcher constructed "an index of central themes and subthemes, which are then represented in a matrix" (Bryman, 2012, p.579) (Appendix 4). Firstly, analytic codes were applied to the body of descriptive codes. For example, descriptive code labels included 'pronoun' (e.g. "share your content"), and 'interaction verb' (e.g. "Discover Auckland's unique heritage"). An analytic code was applied to both as "How the user is encouraged to engage with the site".

An axial approach was used to extend analysis from analytic codes to discovering the dimensions and properties of categories (Saldaña, 2009, p.159). For example, "How the user is encouraged to engage with the site" included dimensions called "Your" and "Our". These correspond to different subject positions where a digital collection suggests the user is. This is just one example of the multiple coding cycles which refined, distilled and clustered individual codes into groups that either corresponded to existing high-level concept categories, or into new categories that augmented those identified through deductive means. This on-going process of interpretation and inductive reasoning allowed the researcher to finally identify six high-level categories in the form of conceptual concerns related to place and explore the thematic variations (Leedy \& Ormrod, 2012, p.97).

\section{Quantitative approaches}

In stage one, quantitative data was generated by: attribute codes, word frequency, and the presence, absence or quantity of particular features or technologies. In stage two, quantitative data was generated by attribute information, respondent identification of particular features or technologies, and the extent to which practitioners agreed or disagreed with various emergent findings. This data was primarily developed into descriptive statistics used in two ways. Firstly, descriptive statistics were used to sketch a picture of every stage one digital collection (e.g CHI type; content formats available), and enable comparison across the stage one sample (e.g. mode content format). Secondly descriptive statistics enabled comparison across the stage one and stage two sample once 
collated, and enabled emergent stage one findings to be validated or challenged (e.g. mode content format across digital collections and as identified by survey respondents). Unfortunately, sophisticated statistical tests were possible due to the small sample size. For example, during cross tabulation of stage two quantitative data, the Chi Square test could not be used to determine statistical significance between variables because the expected frequency was always less than five.

However, the WebCA approach did mean that quantitative data could be resourcefully deployed as a mechanism for the analysing how effectively digital collections engage with place. A functional example of this approach is as follows. The international literature indicates that features enabling user contribution foster a stronger sense-of-place in a digital collection (Von Seggern, Merrill \& Zhu, 2010, p.277). So, for each digital collection, data was recorded on how many different user contribution features it employed, and the presence or absence of potential barriers to using these features (e.g. having to register for the site before using these features). This data was then implemented as magnitude codes within the relevant category 'User Contribution'. Magnitude codes capture “intensity, frequency, direction, presence, or evaluative content" of material (Saldaña, 2009, p.58), so a collection that included a variety of user interface features, that took fewer clicks to access and required no registration, had high magnitude codes under 'User Contribution' (Appendix 5). During analysis these codes were used to compare the intensity of user contribution features within a digital collection and, therefore, how efficiently a digital collection generated a sense-of-place.

\subsection{Validation \& Reliability}

Following Creswell (2014, p.201 - 202), a variety of strategies were used to increase validity and reliability. Firstly, using content analysis as the main methodological approach "indicates that the researcher's approach is consistent" with different researchers from within the same field i.e. Von Seggern, Merrill \& Zhu, 2010 (Creswell, 2014, p.201). Strategies for increasing validity included: triangulation of data from different information sources to "build a coherent justification for themes" and to ensure that themes are all established based on convergence (Creswell, 2014, p.201). Furthermore, any contradictory, 
"negative or discrepant information" is often presented alongside a theme to increase the realism of the account (Creswell, 2014, p.202).

\subsection{Ethical Considerations}

All documents assessed in stage one were publicly available information and no ethical consent was required (Human Ethics Policy, n.d., 4.4). To ensure research practice was consistent with VUW HEC guidelines during stage two, ethical considerations included: voluntary, informed participation and the right to privacy (Leedy \& Ormrod, 2012, p.104; Human Ethics Guidelines, n.d., 2.1). Survey participants were provided with an information sheet prior to answering the survey (Appendix 3 ) and anonymity was ensured since the online survey did not ask for or collect any identifying features e.g. organisation name or ISP address.

\subsection{Limitations}

Despite there being considerable heritage sector interest in mobile mapping applications, location based services are outside the scope of this project.

Resourcing restrictions necessitated a small sample size. Consequently, statistically significant relationships between variables were problematic to identify. Apparent relationships between variables indicated by the data could only be conjectured, so interpretations accordingly derived may not be fully reliable.

This overall small sample size, and the stage one purposive sampling method, may also mean that the sample is not adequately representative of the population. Research findings cannot be extrapolated from this study to the whole population of cultural heritage organisations in New Zealand that engage with place.

A self-administered survey was used as a measuring instrument in stage two. It is possible that definitions and questions on this survey were interpreted not as anticipated, especially since the survey interrogated a complex concept. This means that research findings may be affected by respondent bias. 
Research findings are derived from the interpretations of a single researcher: through content analysis and thematic analysis. This means that the researcher's cultural bias may have affected results. 


\section{Results and Discussion}

\subsection{Introduction}

The results of this study suggest that the concept of place does partly motivate and structure geographically-inclusive cultural heritage practice in New Zealand. Not only did an array of digital collections exhibit place-inclusive components, but anecdotally, the importance of place is indicated by the instinctive responses of many practitioners. One survey respondent noted that the "information that we have is bo[u]nd to places"; another, that "place is a big component of most of the information we capture" ${ }^{1}$. What follows is an in-depth exploration of how New Zealand's digital collections engage with place technologically, functionally, and conceptually. In keeping with the qualitative weighting, each section is organised around a high-level category that emerged during thematic analysis.

\subsection{Instruments of place}

\section{'Seeing' through digital tools}

Roger Downs argues that GIS function as the chief "instrument enabling people to think geographically" (Downs, 1997, p.113). In emphasising instrumental value, Downs compared the role of $20^{\text {th }}$-century GIS to that of $17^{\text {th }}$-century maps: "[g]eography is not in the map; it happens in the mind, although it happens through and because of the map" (Downs, 1997, p.114). These instruments of representation are not coterminous with understanding; rather they provide the lens that guide a particular interpretation: "understanding comes into being because the mind is brought to bear on" representational tools (Downs, 1997, p.114). There are two reasons Downs' argument provides a useful model for understanding how geospatial technology and digital tools can be used to direct the "gaze of the beholder" in New Zealand's digital collections (Downs, 1997, p.114). Firstly, because one specific component of understanding reached 'through' geospatial technology is "sensitivity to place" (Downs, 1997, p.117). And secondly, when asked to elaborate on the value of mapping tools in their digital collections, survey respondents evoked their lens-like function:

\footnotetext{
${ }^{1}$ All un-attributed quotes some from stage two survey long answers.
} 
mapping tools "reveal new connections and new ways of looking at our content and 'revealing it' to the public". In an educational setting, mapping tools "allowed the students to see a collection in a completely new way". The remaining questions are, then, what digital tools are used to 'direct the gaze of the beholder'? And how do various lenses shape 'sensitivity to place'?

\section{The preferred tools and technologies}

Results indicate that the Google Maps API is the preferred instrument for 'directing the gaze of the beholder'. In stage one, eight digital collections employed geospatial technology; of which seven used the Google Maps API. This means $87.5 \%$ of stage one digital collections using geospatial technology used the Google Maps API. In stage two, 12 respondents reported using geospatial technology in their digital collections; of which five used the Google Maps API (Figure 3). In stage two, $41 \%$ of digital collections using geospatial technology used the Google Maps API. Across both stages, $64.25 \%$ of digital collections using geospatial technology used the Google Maps API. This reflects an international trend towards using the Google Maps API within the cultural heritage sector. According to the wider community, the Google suite is ubiquitous because the tools "are not designed for expert use" (Goodchild \& Janelle, 2010, p.4 - 5; Rumsey, 2009, p.1) and they automate the complex processes usually associated with mapping (Goodchild \& Janelle, 2010, p.7;

Dwiggins, 2010, para.24). While it cannot be proven that ease-of-use drives our uptake of the Google Maps API in New Zealand, a similar sentiment was echoed by survey respondents when asked to rate the difficulty of particular factors associated with creating place-inclusive digital collections. Factors associated with identifying and learning to use tools and/or services were consistently reported as easier than factors associated with finding project resourcing (Figure 3). 


\section{Figure 3}

\section{Difficulty of factors associated with building place-inclusive digital collections}

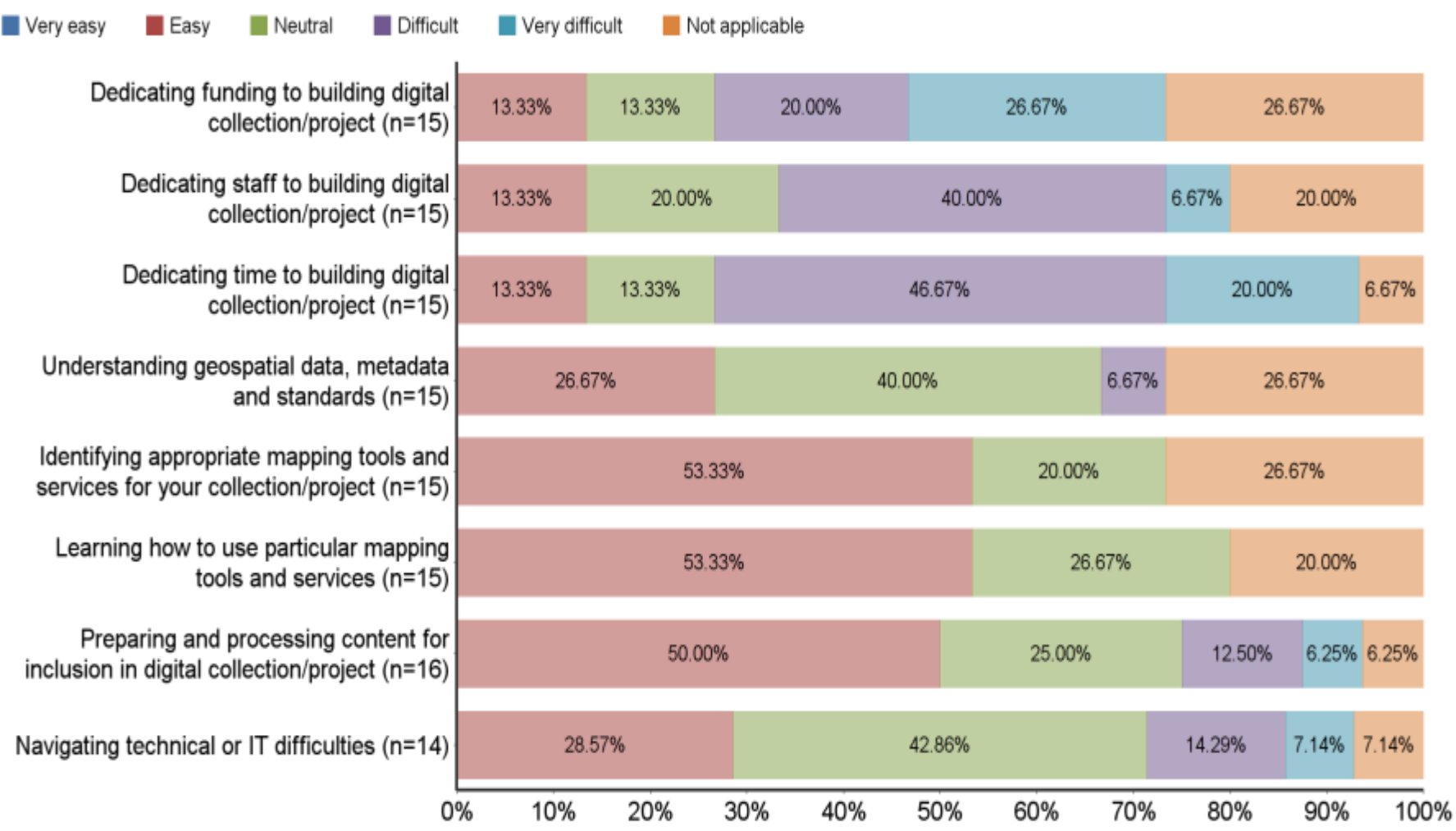

\section{Percentage of Respondents}

While the Google Maps API is the most consistently used tool, there was a striking variety of tools and services identified in stage two by respondents not using the Google Maps API (Figure 4). The seven respondents who selected "Other mapping tools or services" identified six different geospatial technologies: Solr Spatial Indexing, BatchGeo, OpenStreetMap, GeoNetwork, Intramaps, and Flickr. On the one hand, this array may be unsurprising because any geographically-inflected project will require different tools to perform the enormous range of possible processing afforded by geospatial data. BatchGeo is most effectively used for geocoding (BatchGeo, 2014, Features) (Appendix 1); while OpenStreetMap primarily functions as a geospatial database that, for ease of use, also includes some tile serving functionality for data representation (OpenStreetMap, n.d., About). But, on the other hand, the variety of digital tools and technologies identified by practitioners in stage two indicates a valuable willingness to look beyond Google that was not quite clear from stage one. 


\section{Figure 4}

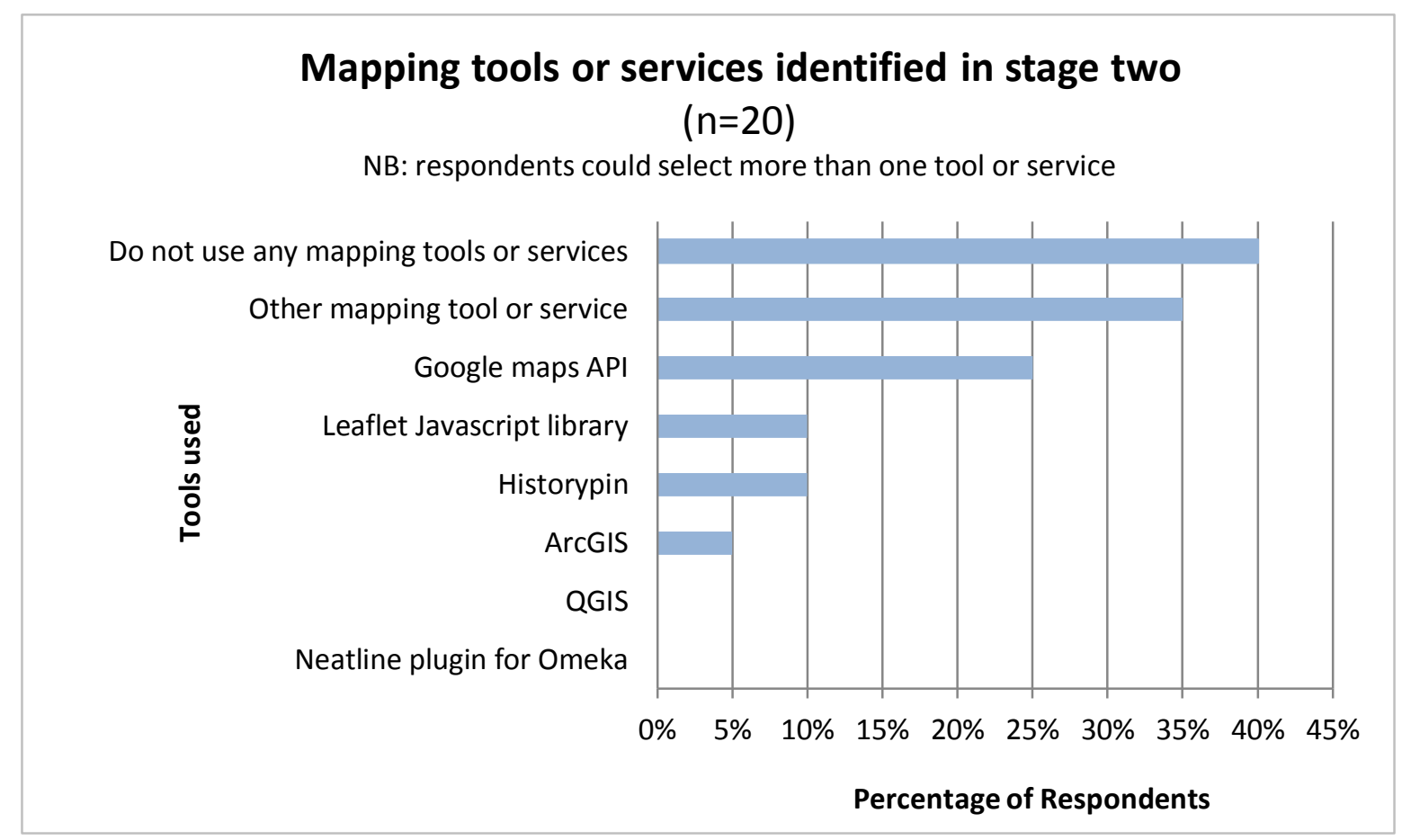

It was anticipated that there would be a significant uptake of geospatial tools aimed specifically at the cultural heritage sector; tools like the "geotemporal exhibit builder" Neatline (Neatline, About, n.d.). Surprisingly, no respondents reported using Neatline in stage two, though HistoryPin had more traction across the whole sample. While only one stage one digital collection used HistoryPin, stage two long answers indicated its value. One respondent's:

digital project has been underway since 2007 and adopted web 2.0 tools early. The disadvantage of this is that they changed and evolved, not always in a helpful way. There are possibly better options available for me to use now: eg History Pin instead of Google Maps and Flickr.

Alongside being valuable in terms of its functionality, even over the Google Maps API, HistoryPin is also valuable as a free resource:

\footnotetext{
We don't always have the necessary platforms to be able to put our online collections into in a way suitable for each project - this is down to budget and staff resourcing. So being able to use third party sites such as Historypin for free has been very liberating
}

One area to follow-up from these findings is the relevance of particular geospatial tools to cultural heritage concerns and cultural heritage organisations' needs. A valuable project 
would be outlining the functional requirements for geospatial technology that supports cultural heritage activities.

\subsection{A sense-of-[a particular]-place}

One clear approach to place is demonstrated by New Zealand's digital collections that seek to generate a 'sense-of-place'. This is no trivial goal because, "sense-of-place is taken to embrace the affective attachment that people have to place" (Withers, 2009, p.640). Generally, sense-of-place digital collections use a variety of technologies, tools and strategies to replicate place as it is comprehended by Tuan and Relph: place is a way of knowing the world through "subjectivity and experience" (Cresswell, 2004, p.20). Although many digital collections demonstrated some aspect of this approach, the stage one examples most clearly demonstrating sense-of-place engagement are The Prow, Upper Hutt Recollect and Central Hawke's Bay Kete. There were four main strategies which corresponded to generating a sense-of-place.

\section{Collaboration: user-contribution and personalisation}

Sense-of-place digital collections firstly encourage collaboration by emphasizing usercontribution features and content personalisation strategies. In stage one, the most common collaboration features were: sharing content via social media, adding new content in the form of "stories" and "memories", adding comments, bookmaking or set-making and subject tagging. In stage two, respondents identified a similar array of collaborative functionality in their place-inclusive digital collections (Figure 5). 


\section{Figure 5}

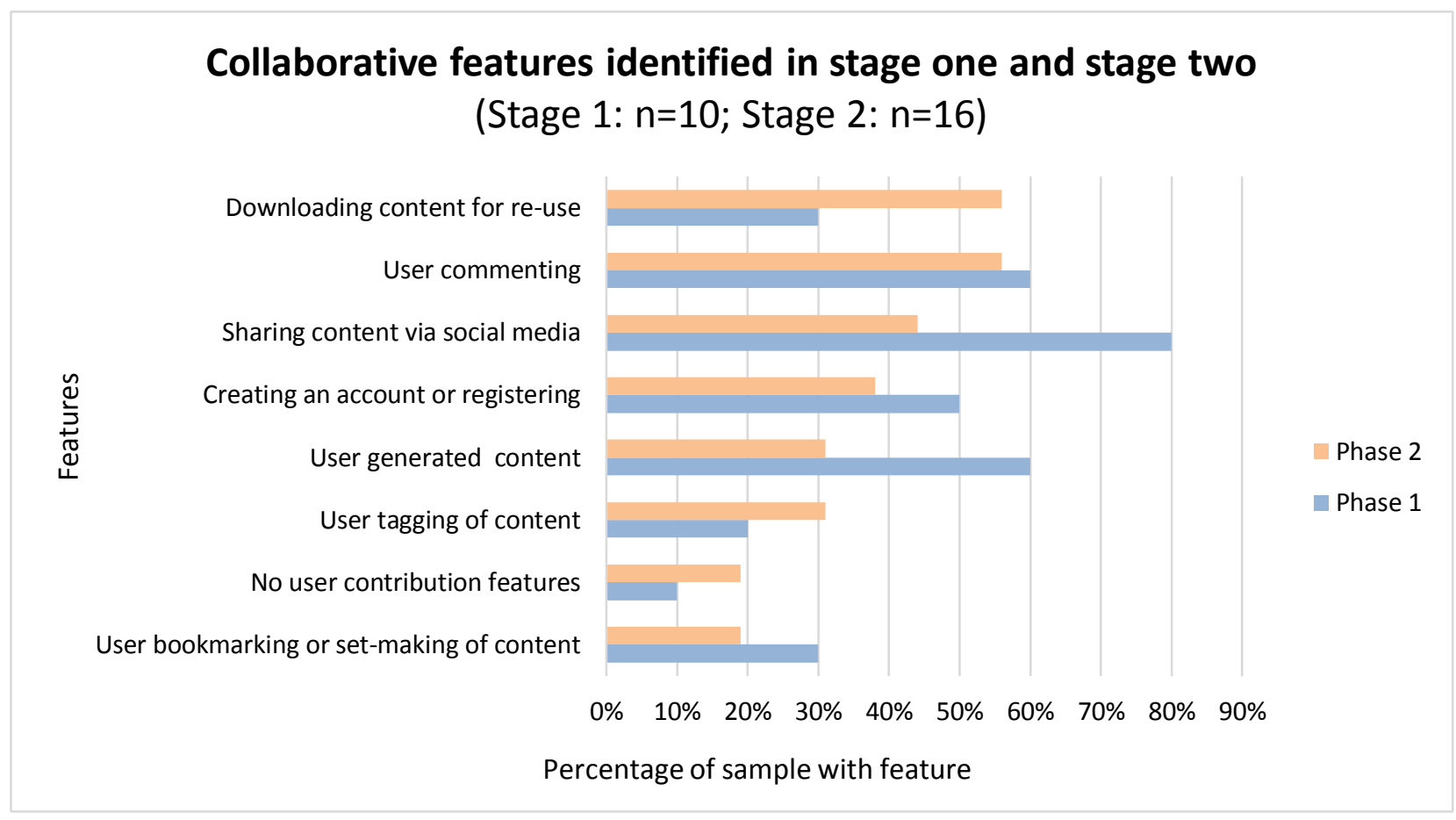

This emphasis on collaborative features channels three recommended strategies for generating a sense-of-place in a Web-based environment. Firstly, a digital collection should "allow personal experience to be recorded privately and publicly". Secondly, it should include "personalization features" (Farrelly, 2013, Conlcusion). And lastly, the:

capability of adding user-generated content, whether it is original content or addition as to supplied digital objects, enriches a digital collection and promotes a 'sense of place' (Merrill, Von Seggern \& Zhu, 2010, p.277)

It is not hard to see how an emphasis on user-contribution and personalisation features reflects Tuan and Relph's conception of place. For these theorists, the qualities of place are inseparable from personal understanding and subjective experience: "the given cannot be known in itself. What can be known is a reality that is a construct of experience, a creation of feeling and thought" (Tuan, 1977, p.9). So, in the digital world, user contribution and personalisation features privilege - and seek to mimic - this inseparability of subjectivity from the given, physical world: "content collaboration captures the personal experience as it relates to the place and collection" (Merrill, Von Seggern \& Zhu, 2010, p.277).

Collaborative features encourage users to bring their personal understanding to collection content. 


\section{Personalised narrative}

The sense-of-place approach strongly associates user-contribution with personalised narrative. The Central Hawke's Bay Kete "would like to capture the memories and activities" of the region (Central Hawke's Bay District Libraries, n.d., Home). Upper Hutt Recollect asks users to "contribute your own knowledge and memories about the items in these collections, as well as create personal collections of your own" (Upper Hutt City Library, 2014, Home). The prow invites you to "add your own story" (Nelson City Library, Tasman District Library, Marlborough District Library, Nelson Marlborough Institute of Technology, \& The Nelson Provincial Museum, n.d., Home). A term-frequency analysis of words used to describe content shows that place-inclusive digital collections cluster content around the concepts of 'stories, 'history', 'heritage' and 'memories'. Quakestories' refrain demonstrates this neatly: "Canterbury, your place, your stories" (Ministry for Culture and Heritage, 2011, Home). One survey respondent stated their organisation's "specially themed online exhibitions" capture "place in relation to particular Auckland regional locations...Or the stories \& memories relating to people who have lived in a particular area". While an emphasis on 'history' and 'heritage' is unsurprising from within the sector with a mandate to "preserve culture" (Deegan \& Tanner, 2006, p.1), the other two phrases are more telling. 'Memories' reflects personalisation since there is nothing more personal or subjective than something only we have direct access to; and 'stories' clearly privileges linear narrative over other forms of representation (e.g. pictorial).

Describing collection content using language that makes it synonymous with personalised narrative is consistent with a recommendation that digital information sources should "consider affect" as a way to meet people's "place-related needs" (Farrelly, 2013, Conclusion) ${ }^{2}$. Firstly, emphasizing 'memories' echoes Relph's view that memory is potent for constructing our relationship to places (Relph, 1976, p.31): “[s]ense of place is the meanings an individual has toward a place...such meaning can be comprised of personal feelings or memories, involving the sensual, aesthetic, [or] experiential" (Farrelly, 2013, Literature Review). 'Storytelling' is significant because it superimposes a 'time' component over digital collections' primarily static representational capacity. For many theorists "sense

\footnotetext{
${ }^{2}$ A digital collection was interpreted as 'considering affect' if it encouraged users to understand collection content in ways consistent with how people make meaning in their lives (Farrelly, 2013, Literature Review).
} 
of place implies that we can see the connections between what happened in the past and the location we now inhabit" (Dwiggins, 2010, para.2; Relph, 1976, p.31) so narrative is a powerful way to knot co-ordinate systems, digital maps and heritage content with sense-ofplace (Historypin, n.d., About; Harkema \& Nygren, 2012, para.11). For some, stories are the most important feature for sense-of-place digital collections. Storytelling covers potentially limited geospatial technology with a layer that is more consistent with how we interpret our world: "people are confused by maps, they can handle textual meaning of place" (GECO, 2012, Humphrey Southall, 2012, para. 2 - 3).

\section{Shared understanding: social interaction and social navigation}

Sense-of-place sites balance their substantial emphasis on subjectivity by encouraging user engagement in ways consistent with Relph's argument that sense-of-place arises from shared meaning, and the interchange between individual and community identity (Relph, 1976, p.33): "common experience is unquestionably an important element in understanding place" (Relph, 1976, p.36). In practice sense-of-place collections' collaborative features are accompanied by features allowing subjectivity to be shared and consequently generate or re-affirm collective understanding. Since digital collections are also websites, most usercontributions are automatically 'shared' because they are publically available, but some collections expand broadcast mode. These collections encourage users to connect directly with other users through social interaction features, or access content through sociallyinformed navigation features. For theorists, "social navigation features that...provide connections with other users further enhance place-based sites" (Von Seggern, Merrill \& Zhu, 2010, p.281).

Six stage one digital collections included a commenting function. While this familiar Web 2.0 feature does not necessarily indicate a deliberate desire to encourage social interaction between users, in some cases this functionality was attached to every item and presented as a peer-to-peer discussion forum (Figure 6). The Prow and the $28^{\text {th }}$ Māori Battalion site encourage users to access content through a list of latest comments added by other users (Nelson City Library et al, n.d., Home; Ministry for Culture and Heritage, n.d., Home) (Figure 6). You can navigate the Christchurch Art Gallery Collection Online via "My Gallery sets": digital collections curated and shared by other users (Christchurch Art Gallery, n.d., My 
Gallery). Features like these allow users to sidestep a collection's formal structure and navigate based on contributions from other community members. Navigating via "other users' pathways" is a powerful way to re-affirm shared understanding (Von Seggern, Merrill \& Zhu, 2010, p.278). Regrettably, there was no capacity to confirm this 'shared understanding' theme from stage two data.

\section{Figure 6 Approaches to socialisation and social navigation in stage one}

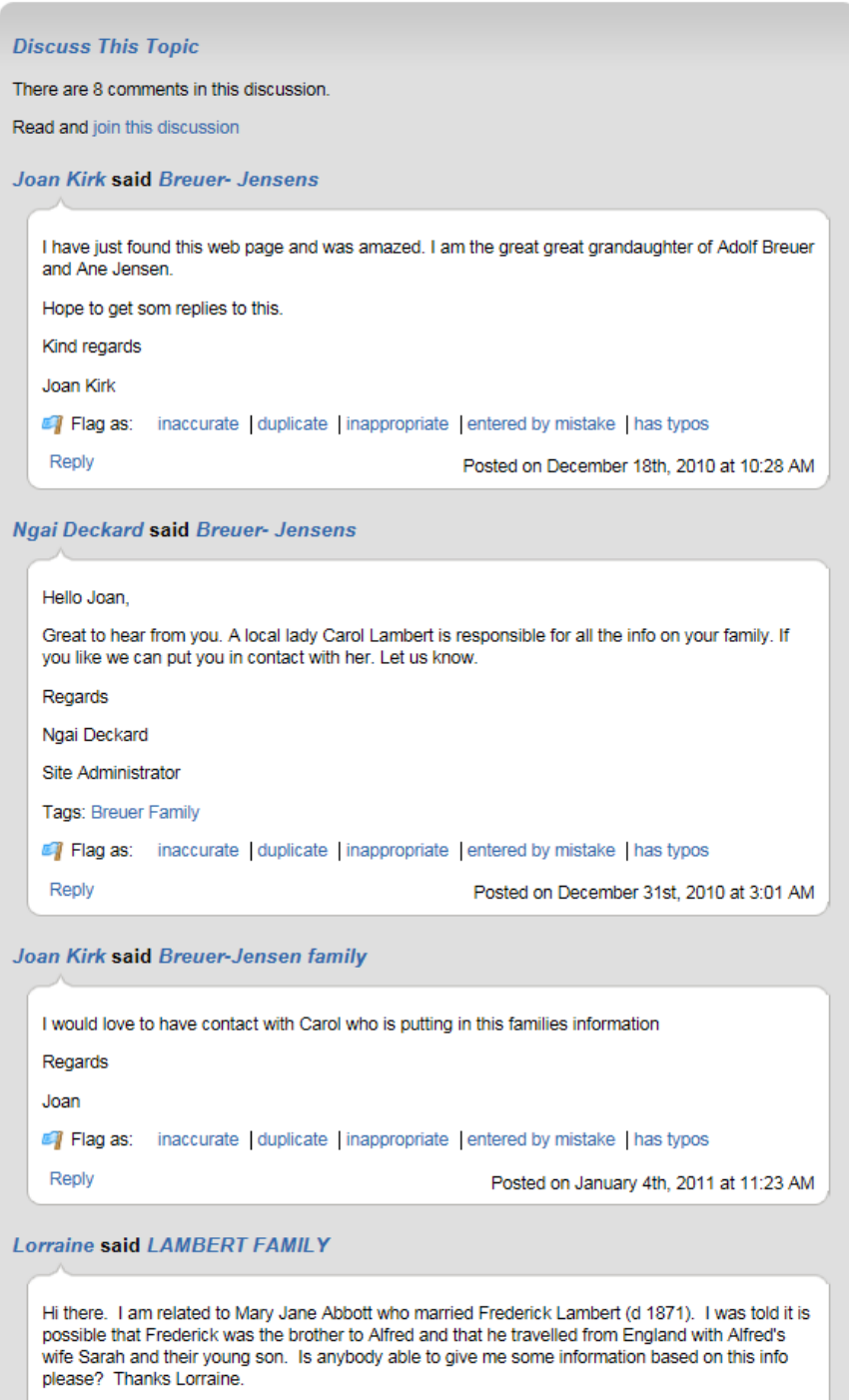

\section{Contribute}

Add your stories, photos, audio and more..

Start contributing now

Already a contributor?

Log in here

\section{Latest comments}

Karewai Mac commented on William Hunia

Mateohorere commented on Reihana Tangoiro

Mateohorere commented on Reihana Tangoiro

saumua commented on Joseph Andrew Berghan

Mary Lynne Brown

commented on Rangi Brown

See all comments 


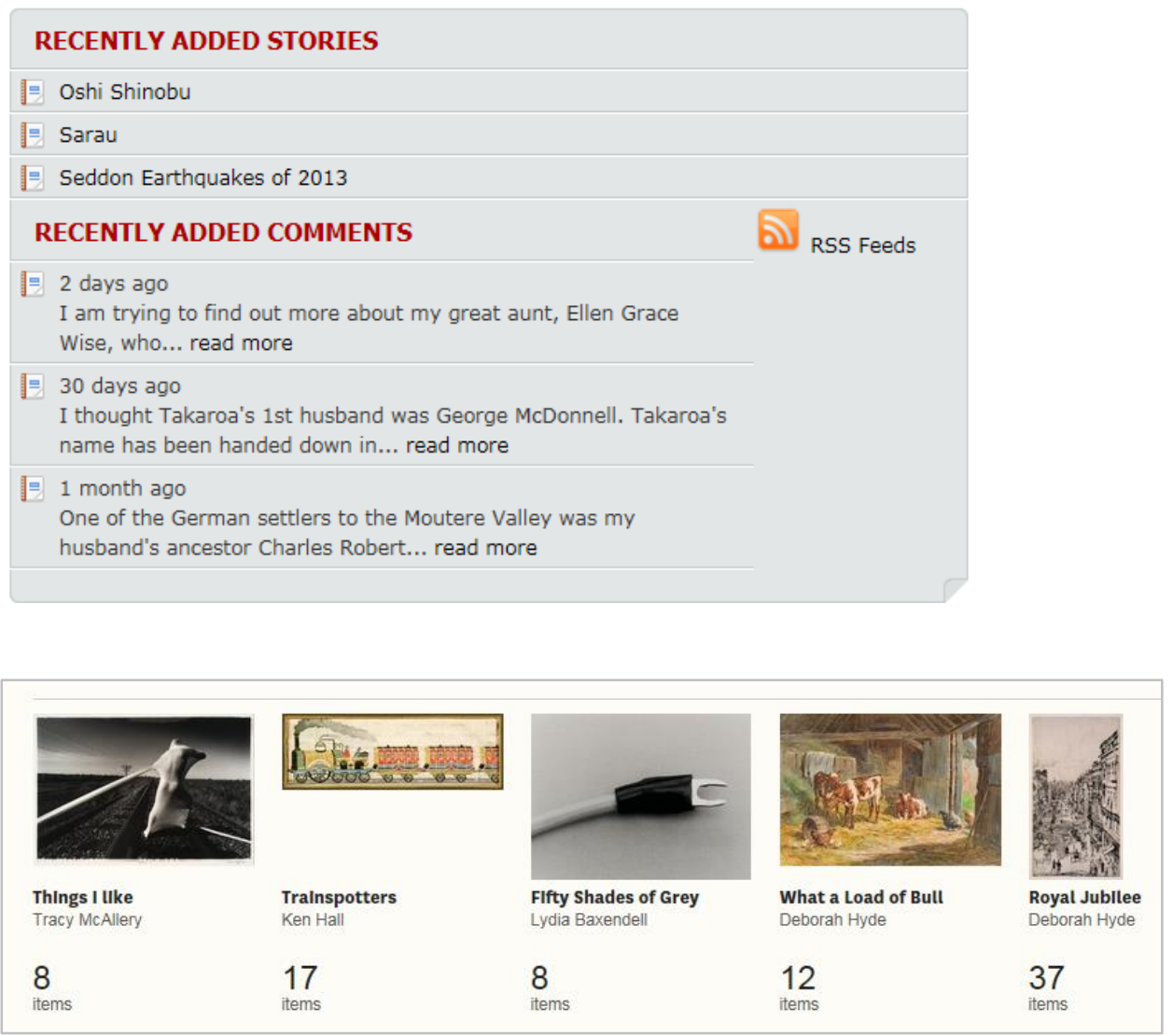

\section{Multimodal understanding}

Sense-of-place collections include a variety of content formats and content types. This is consistent with an argument that "sense of place arises from diverse information sources [and] is multimodal" (Farrelly, 2013, Abstract). This also reflects Tuan and Relph's argument that sense-of-place develops through many sensory channels: the "physical and representational aspects of a place such as the natural and built setting" (Farrelly, 2013, Literature Review), our "unself-conscious participation" or "habitual action" in that place (Cresswell, 2008, p.57), and even "through a more symbolic register" like monuments (Cresswell, 2008, p.57). To mimic the multimodal development of sense-of-place, the digital sphere uses a variety of formats and information sources. Accordingly, both stage one digital collections and stage two respondents indicated a variety of content formats and types (Figure 7; Figure 8; Figure 9). 
Figure 7 Browse functionality highlighting variety in content format and content type
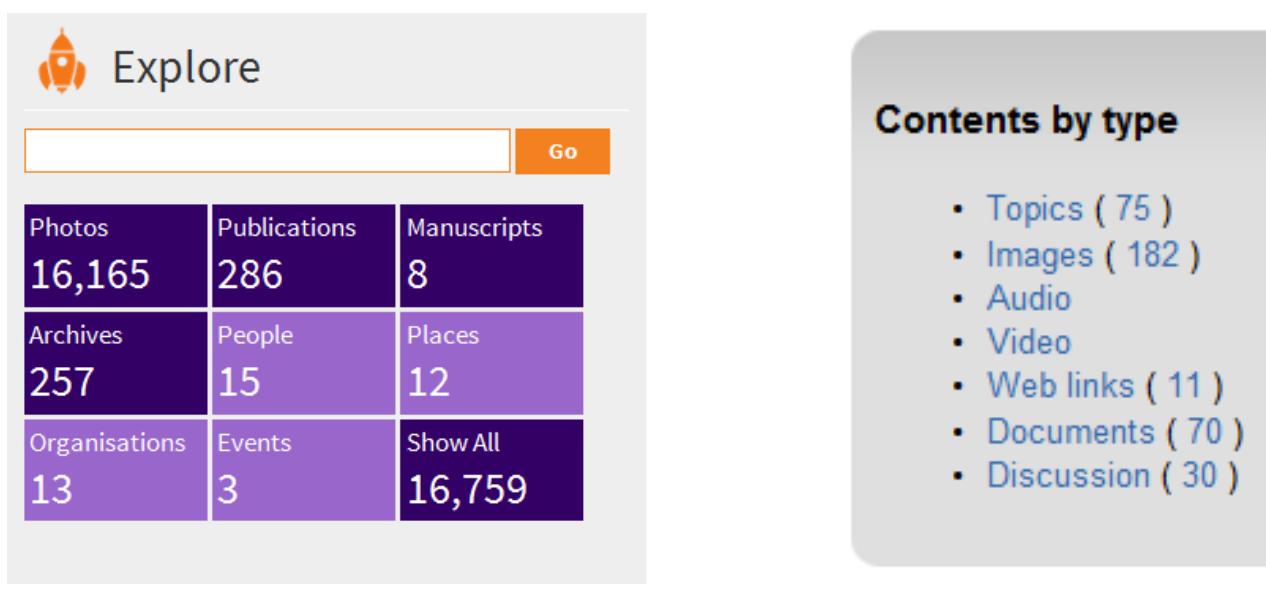

Figure 8

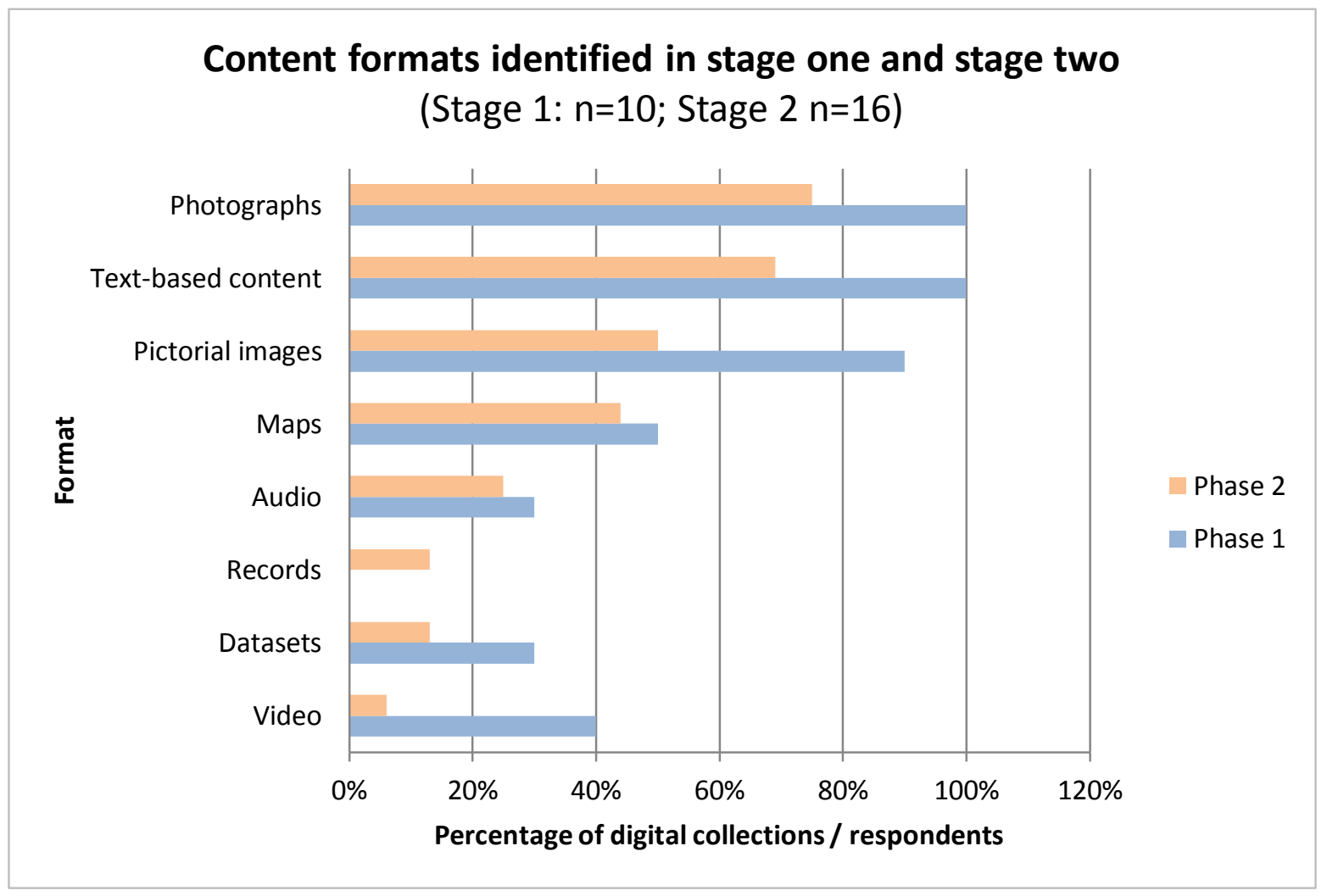




\section{Figure 9}

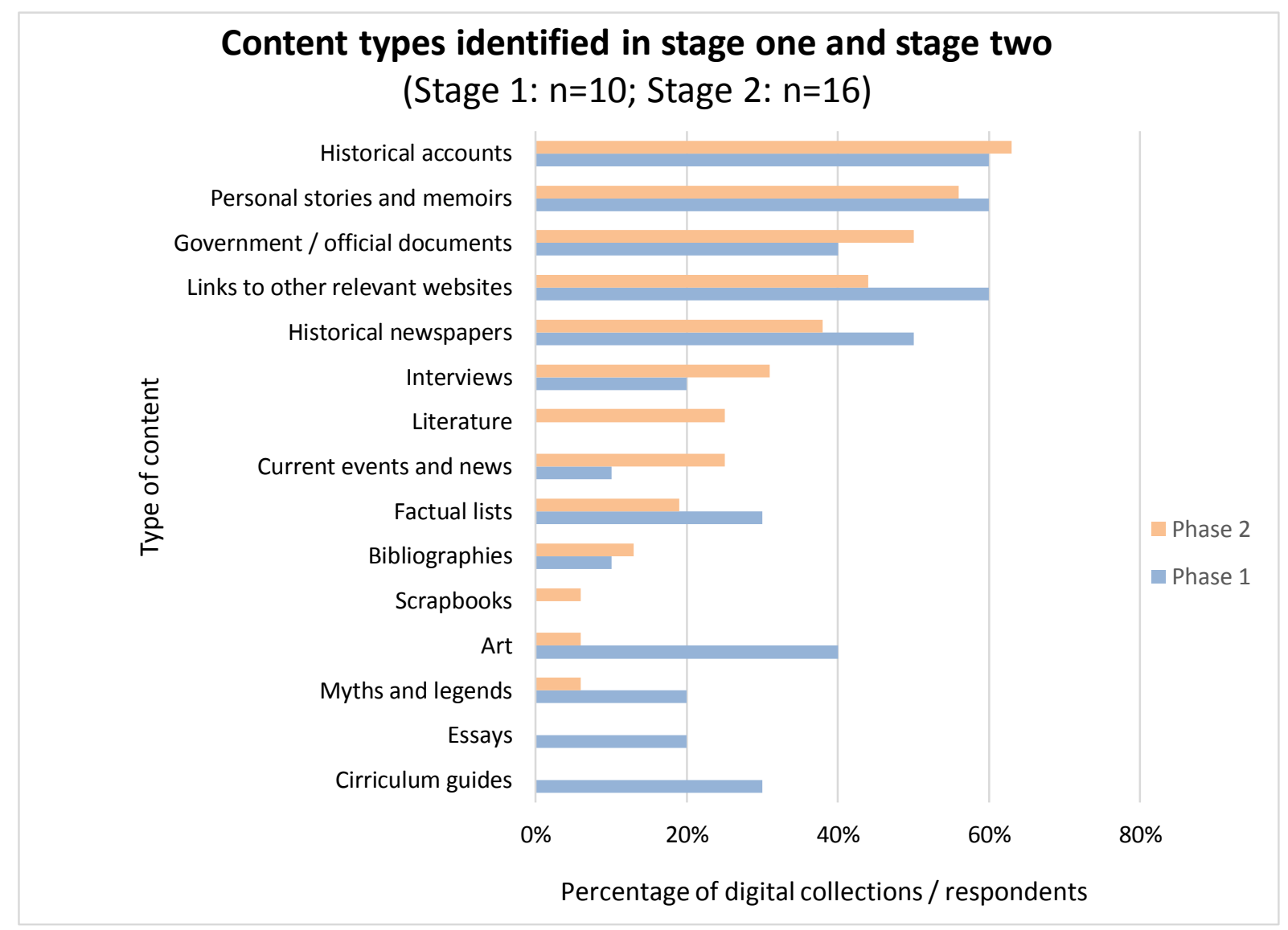

The most common content formats were photographs and textual material. The most common content types were historical accounts and personal memoir. In combining format and type, collections frequently delivered textual content with embedded supplementary material: visual representations of the place under discussion; digitised primary resources that are also transcribed. From this perspective, digital maps and geospatial technology are only one component for generating a sense-of-place: "maps help to orient the user and graphically supplement other material formats by providing alternate views" (Von Seggern, Merrill \& Zhu. 2010, p.275; 276). It is visual and textual materials that do the conceptual or emotive heavy-lifting: "materials produced by individuals add a rich first-person perspective" (Von Seggern, Merrill \& Zhu, 2010, p.275). This sidesteps unease surrounding the fact that geospatial technology articulates "Euclidean spaces quite well, but the sociallyproduced...notion of place has to date proved elusive to digital representation" (Fisher \& Unwin, 2005, as cited by Edwardes \& Purves, 2007b, p.107). In sense-of-place collections, geospatial technology alone is not responsible for representing place. 


\section{A place-making lens}

Ultimately, if we bring Roger Downs' perspective to the digital tools and features within sense-of-place digital collections, then we see that they are "engaged in place-making" (Cresswell, 2004, p.5). Place-making is an ontological act: sense-of-place collections encourage users to define or understand somewhere as a place; to confer somewhere with the status of place. Indeed, digital collections that generate sense-of-place usually do this in relation to a specific area: they contain "heritage material relating to Upper Hutt" (Upper Hutt City Library, 2014, Home) or "stories from Nelson, Tasman and Marlborough" (Nelson City Library et al, n.d., Home). In stage one, $60 \%$ of digital collections stated a similar mandate to represent a particular place. In stage two, $57 \%$ of respondents indicated that their digital collections "use a particular place as the main thematic focus".

This exploration indicates that the strategies used for ontological definition can correlate to Relph's three layers of "place identity" (Relph, 1976, p.46). A "place's physical setting [1]" is captured through representations of and references to that place. The place's "activities, situations, and events [2]" are captured through the 'memories' and 'stories' sought from users. And finally, the "individual and group meanings created through people's experiences [3]" are captured through the collaborative and social-interaction features (Seamon \& Sowers, 2004, p.45). Inevitably, plotting points on a digital map cannot generate a sense-ofplace because "place cannot simply be described as the location of one object relative to another" (Jordan, Raubal, Gartrell \& Egenhofer, 1998, p.2); however, this section has indicated that toolkit of particular features encourages users towards a sense-of-place understanding.

\subsection{The Semantics of Place}

Alongside approaching place in ways consistent with Tuan and Relph's sense-of-place, New Zealand's cultural heritage organisations also engage with place in ways that confirm Timothy Cresswell's assertion that place is a term "wrapped in common sense" (Cresswell, 2004, p.1). There is significant semantic flexibility in how the word place is deployed in digital collections; and how cultural heritage practitioners use or define it. Firstly, and unsurprisingly, this implies that the term place is as a slippery within New Zealand's cultural 
heritage sector as it within any other. And secondly it may indicate that the sector has not had substantial cause to reflect on the meaning of place or delineate a distinct meaning of place for ourselves. We may not even need to. The stage one digital collections that best demonstrate the semantic approach to place are Te Papa Collections Online, The Prow, Upper Hutt Recollect and Central Hawke's Bay Kete.

\section{Place as location}

In stage one, the word place commonly appeared linked to two components of collections: either attached to item records as metadata, or used at broader level to thematically organise collections. As an example of the former, Te Papa Collections Online lists "Related Places" at the item level (Te Papa Tongarewa, n.d.) (Figure 10). "Related Places" are further qualified into categories which define the item's relationships with that place and the hyperlinked place-name itself takes the user to a separate entity-record for that place. This record lists all collection items associated with that place, and includes information like latitude / longitude derived from the Getty Thesaurus of place names. Here, the word place functions simply as a descriptive metadata field. This is not surprising because geographic identifiers like toponyms are common within many metadata schemas, including Dublin Core's 'Coverage' field (Taylor \& Joudrey, 2009, p.214). Deploying the term place like this is very functional: it is not an interrogation of affective attachment. Rather, this use refers to the quality of place Agnew defines as "location": "the grid references we attach to portions of the earth's surface by...latitudinal and longitudinal positioning" (Withers, 2009, p.639). Given the entity record for Wellington - and the appropriate scale - we could put Wellington on the map. To Cresswell and Agnew, this substitution of the word place for any identifiable geographic location is an entirely justified use of the term in everyday language (Cresswell, 2004 p.11). However, despite this quality of place appearing in stage one, no stage two respondents selected the definition that corresponds to "location" as the best definition of place.

\section{Place as locale}

Place is also often evoked at a higher level as an organising theme of a whole digital collection (Figure 10; Figure 7). As a thematic organiser applied to an entire collection, place 
is usually evoked alongside themes like 'people', 'events', and 'organisations'. In this case, the word seeks to create a slightly richer or more metaphorical impression than strictly referring to geographic locations. The Prow aggregates stories under its place tab called "The lime and marble of Takaka Hill" or "The naming of Nelson" (Nelson City Library et al, n.d.). The Central Hawke's Bay Kete aggregates topics under its place drop-down called "Flemington and the Porangahau Purchase" or "Mount Vernon and the Harding Family" (Central Hawke's Bay District Libraries, n.d.). This use of place reflects Agnew's notion of "locale": the word place is a substitute for "the material setting for social relations - the actual shape of place within which people construct their lives as individuals" (Cresswell, 2004, p.7). You cannot use this version of place to locate somewhere on a map, but you develop an understanding of the area's social relations, culture and history.

Place as 'locale' was strongly present during stage two. The survey respondent who stated that: "local govt records are about...the functions of what the council did...and where this occurred can help the story about the record" is conflating place with "where [an event] occurred". This is a typical synonym for locale. Another respondent stated their interest lay in "people who have lived in a particular area... [and] locations and communities e.g. Chinese market gardeners in Auckland CBD and the suburbs". For this practitioner, place is not defined by co-ordinates but by the presence of an identifiable community group. This is consistent with an understanding of locale rather than location since a single, static geographic area is not a perquisite for locale: "places are not always stationary" (Cresswell, 2004, p.7). For some even, "place is essentially its people and that appearance or landscape are little more than a backdrop of relatively little importance" (Relph, 1976, p.33). In stage two, $80 \%$ of survey respondents identified the definition that corresponds to "locale" as the best definition of place. 


\section{Figure 10: Approaches to the word place in stage one}

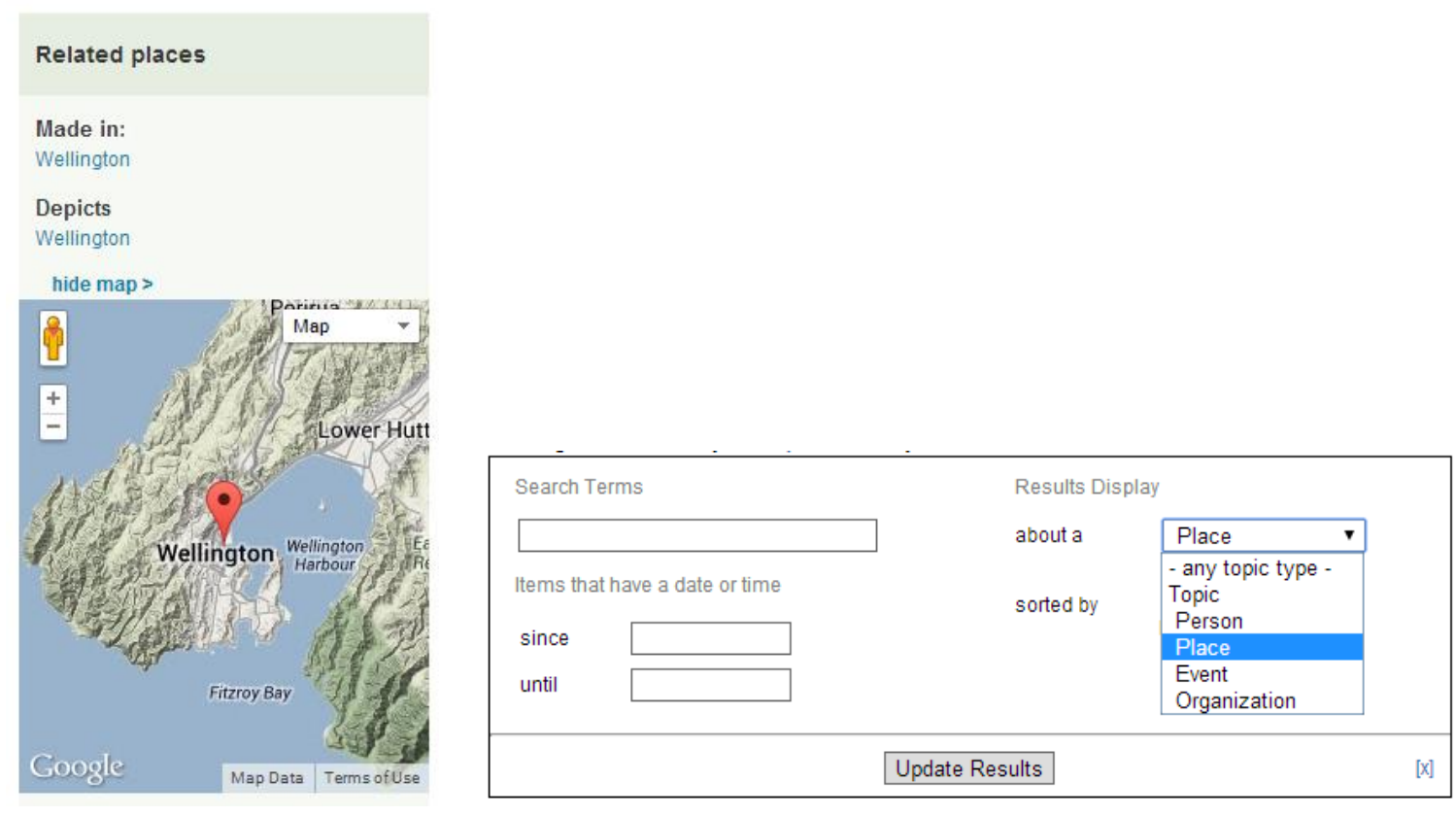

\section{The scale of place}

Across stage one and stage two, place ranged considerably in scale. In the Central Hawke's Bay Kete, the list of places include specific towns (e.g. 'Otane', 'Waipawa'), notable buildings (e.g. 'Ashcott Homestead', 'CHB Settlers Museum'), and regional physical features (e.g. 'Beaches and Coastal Regions') (Central Hawke's Bay District Libraries, n.d.). In Upper Hutt Recollect, places also include suburbs (e.g. 'Trentham') and streets ('Main Street, Upper Hutt) (Upper Hutt City Library, 2014). Te Papa Collections Online includes place entity records for cities, suburbs and countries (Te Papa Tongarewa, n.d.). Stage two responses also indicated a vast range for the scale of place from buildings, to regions, to whole of New Zealand. When asked what area their mapping activities focused on, one respondent replied: "In my situation the places themselves are the focus, the houses, signs on houses, and later, stories from people who lived in the houses"; another stated: "our local region". Region was also evoked by another respondent who said they collected "anything related to our district". Finally, one respondent sought to "show the national scope" of historical activities. 
This attitude to scale is consistent with two observations: firstly that place can range in size from "the corner of a favourite room...[to] the globe (Cresswell, 2004, p.11). In New Zealand's digital collections areas of any size can exhibit place-like qualities. Secondly, the common conflation of 'regions', 'districts' and other localised geographic units with place demonstrates that, despite the first point, "most often the designation of place is given to something quite small in scale, but not too small" (Cresswell, 2004, p.11). Our digital collections' approach to scale is delightfully inconsistent: it reaffirms that we can never decide a priori on the qualities of place because there is not one size, type, kind, or necessarily any persistent qualities, of place. However, this finding indicates that our digital collections do encourage users to understand the world as a series of places rather than groupings of other entities. The word place is shorthand for an epistemological stance:

When we look at the world as a world of places we see different things. We see attachments and connections between people and places. We see worlds of meaning and experience (Cresswell, 2004, p.11).

It is appropriate that the cultural heritage sector is interested in a world of places; that our digital collections are interested in Wellington, and the meaning that simple toponym connotes, rather than $-41.2889,174.7772$. Place, in its common-sense capacity, hints at this view.

\section{A role for common-sense-of-place}

Some theorists argue that a common-sense understanding of place is conceptually "anaemic" because it does not capture the human understanding of place in any significant way (Seamon \& Sowers, 2008, p.43). However, while the word place is not deployed consistently and could never function as a synonym for human experience, it is also clear that a common-sense approach to place serves useful functions. Firstly, for the cultural heritage sector, place has distinctive value when deployed simply as descriptive metadata. We need a variety of perspectives to comprehensively record "the identifying characteristics of an information resource" (Taylor \& Joudrey, 2009, p.103). Place is valuable precisely because it is semantically flexible enough to substitute both location and locale: it can 
reflect a variety of geographic constructs in a way that phrases like region, district and area do not.

Secondly, without a common-sense understanding of place it may be difficult to engage with the richer aspects of the concept at all: people have an instinctive understanding of place that - when not subjected to critical reflection - allows us to communicate with each other regarding one of the more important components of how we understand the world (Relph, 1976, p.30; Cresswell, 2004, p.1). One survey respondent neatly evokes both of these points by stating: "We maintain an authority control database and capture...places in our documents which we submit to our database". Finally, it is worth noting that the common-sense approach is not mutually exclusive with the sense-of-place approach: The Prow, the Central Hawke's Bay Kete and Upper Hutt Recollect all engage with place in both ways. A dual approach to place allows a digital collection to leverage the common-sense understanding for ease-of-interpretation, and also engage with place on a richer level.

\subsection{The Value of Place}

Regardless of whether a collection approaches sense-of-place or common-sense-of-place, results indicates the concept has considerable practical value; and that practitioners are very practice-oriented in their consideration of place. Two points stand out: firstly, place has value within traditional information management processes but also in opposition to traditional information management processes. Secondly, that when discussing place, practitioners did not frequently separate the concept from the processes associated with representing it and engaging with it.

\section{Place and traditional information management}

No stage one cases were recordkeeping projects, so an unexpected theme that emerged from stage two was evidential value of place where records are concerned ${ }^{3}$. When survey respondents were asked why they selected particular features to represent in digital collections, one respondent answered: "local govt [sic] records are about...the functions of

\footnotetext{
${ }^{3}$ This may be an example of how respondent interpretation affected the sample: there may be a difference between stage one and stage two because the digital collections referred to by stage two respondents are not publically accessible; while only publically accessible collections were assessed in stage one.
} 
what the council did in a particular time, and where this occurred can help the story about the record". Another respondent stated that capturing information about place was just consistent with their obligations "under the PRA". One respondent stated that place enhances "description of the records". At one level, this just indicates that recordkeepers as well as heritage practitioners (or, at least, those involved with both) engaged with place. On another, it suggests that place has value as straightforward component of processes like arrangement and description.

\section{Place in opposition to traditional information management}

Results more consistently indicated that place has value by enabling unconventional approaches to traditional information management processes. Specifically, this project is consistent with international literature that suggests: places, mapping tools, and map-based navigational interfaces combining the two, provide meaningful collection discovery and enable greater access to content (Dodsworth \& Nicholson, 2012, p.103; Chen \& Notviett, 2010, p.160; Dwiggins, 2011, para.8). Seven digital collections used an embedded Google Map application that visualised items' geographic component using the familiar map pin (Dodsworth \& Nicholson, 2012, p. 104) (Figure 11). In most cases this functioned like a visual index embedded within a collection's IRS components or item records. Map points provide access to surrogate records which the user clicks through to access the full item record (Dodsworth \& Nicholson, 2012, p.103; Chen \& Notviett, 2010, p.160). The map application then supplements traditional information retrieval strategies like browse or search features to provide access to content. Interesting, these applications only really varied according in the size of the map. One slightly different approach was the Auckland city Libraries Historypin which uses the map as an entire collection delivery service: full item records and digitised content was layered over the navigational interface (Harkema \& Nygren, 2012, para.8) (Figure 11). 


\section{Figure 11: Map-based navigational interfaces in stage one}
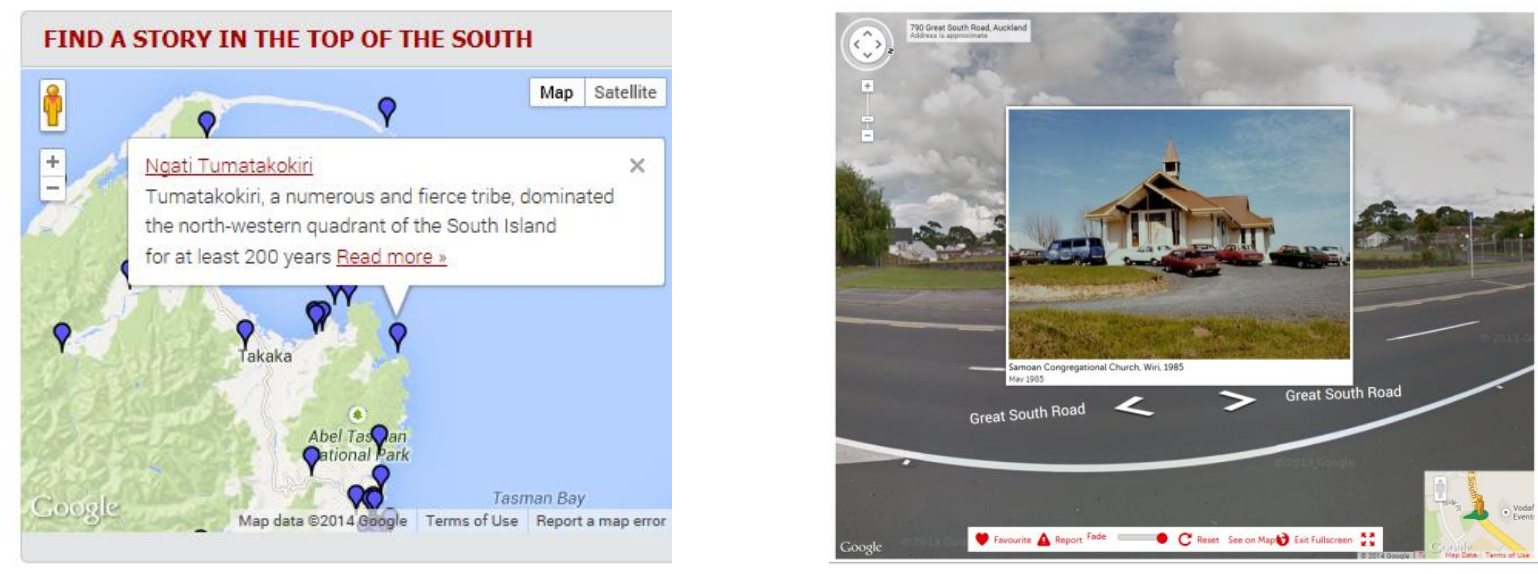

Stage two confirmed this notion that place is significantly linked to access, and to the representational tools that enable access. Maps "provide a visually effective access point to the collection" or "another access point for the collection" or a "new means and methods of discovering a collection". Alongside thinking of the 'access value' place offers in quite instrumental terms, some practitioners evoked a broader construction of access: "getting our collections out there among the public [and] making them accessible". Another stated that mapping "has made people more aware of our collections and raised our profile". Generally, responses demonstrate a strong sense of 'newness': maps provide "new connections and new ways of looking" in contrast to traditional navigation and retrieval interfaces.

While results indicate that place has value in relation to map-based collection interfaces it's difficult to interrogate that belief further or explain the link. Some survey responses were consistent with a perception that map-based collection interfaces are intuitive. When asked what motivated the use of mapping tools in their place-inclusive collection one respondents answered that it made the collection "more 'readable'". Another stated that "the information that we have is bo[u]nd to places. Representing them spatially enables the most intuitive use of the information we hold". This fits with the idea that mapping places enables the "organic and spontaneous exploration" of collections (Harkema \& Nygren, 2012, para.11; Chen \& Nottviett, 2010, p.160) and "reconstruct the true context of records" when traditional indexing has rendered it "incomprehensible" (Dwiggins, 2010, para.8; Clough, Tang, Hall and Warner, 2011, p.127). 


\subsection{Place, Geospatial Technology and Web 2.0}

The most complex findings surround the fact that features and strategies associated with place-inclusive digital collections can be deployed in a context that seems entirely separate from place. This leads to intriguing taxonomic questions: what is the magic ingredient that makes a digital collection place-inclusive? The three digital collections which best illustrate this are the 28th Māori Battalion site, the Christchurch Art Gallery Collection online, and The Bulldog and the Battlecruiser online exhibition.

\section{Place is more than the sum of its parts}

Some collections ingeniously deploy Web 2.0 features or geospatial technology but do not do not necessarily generate a sense-of-place, or even deploy the word place. The $28^{\text {th }}$ Māori Battalion site embeds items in an interactive story that unfolds through space and time, using an interactive map and timeline interface (Ministry for Culture and Heritage, n.d., Map) (Figure 12). The site tells "The Story of the $28^{\text {th" }}$, and includes numerous usercontribution and social-interaction features (Figure 6). It is also significantly multimodal: it demonstrates the most resourceful audio component of any stage one digital collection by overlaying the collection homepage with a haka (Ministry for Culture and Heritage, n.d., Home). The Bulldog and The Battlecruiser similarly demonstrates change over time by combining an interactive map and timeline interface, while strongly encouraging multimodal engagement with content and user-contribution (Auckland War Memorial Museum \& Torpedo Bay Navy Museum, 2013, Home). The clear presence of these features should indicate that The $28^{\text {th }}$ Māori Battalion site and The Bulldog and the Battlecruiser are place-inclusive digital collections (Figure 12). 


\section{Figure 12: Interactive features correlating with place-inclusive sites in stage}

\section{one}
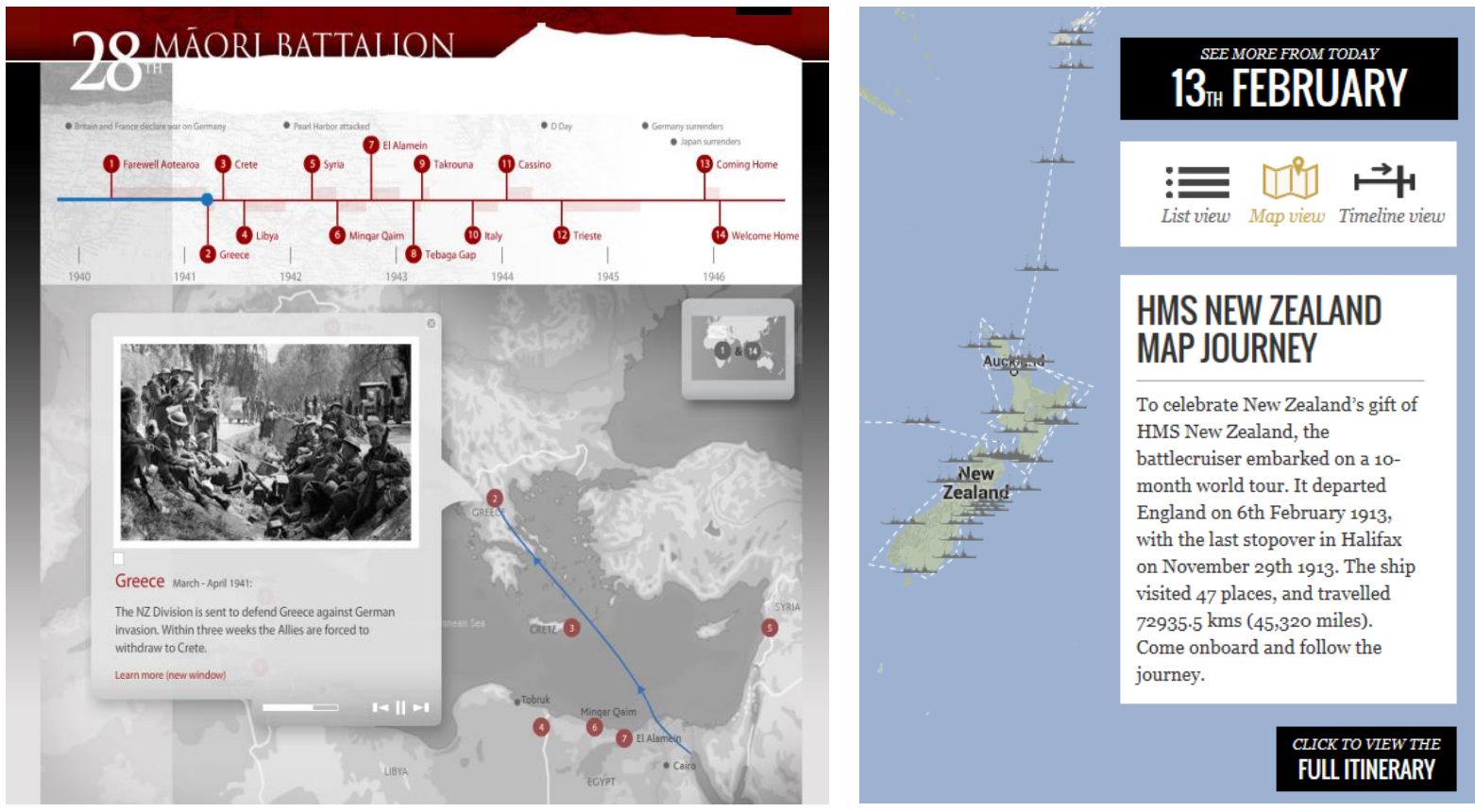

Despite this, these collections do not evoke any place-inclusive lens identified by this project: users are not overtly encouraged to confer a particular location with the status of place or see the world as a series of places. Unfortunately, understanding how place functions relative to these collections is not even as simple as declaring them theoretically incompatible with the qualities of place: pertinently for the Bulldog and the Battlecruiser, even "a ship...may become a special kind of place for people who share it on a long voyage" (Cresswell, 2004, p.7). This site also uses a panoramic view of sea, animated and repeated on loop, for collection backdrop to make users feel like they are standing on the ship (Auckland War Memorial Museum \& Torpedo Bay Navy Museum, 2013, Home). This distinctive immersion reflects the idea that "animations, panoramic images, sound, and virtual reality can provide a strong 'sense of place'" (Ehrhardt and Gross, 2000, as cited by Von Seggern, Merrill \& Zhu, 2010, p.275). How can The Bulldog and the Battlecruiser be theoretically and functionally consistent with place but not seem to invited users to understand the ship as place?

This question has two potential answers. Firstly, it is possible that engaging with place could be completely implicit within a digital collection. This would be consistent with Relph's 
phenomenological assertion that place-based understanding is a pre-scientific fact of consciousness (Relph, 1976, p.7). The Bulldog and the Battlecruiser does not need to formally indicate its engagement with ship-as-place because the collection leverages our innate sense-of-place regardless. Conversely, it is also possible that engaging with or approaching place must be a deliberate, quite overt act to be effective. Otherwise, a site that uses geospatial technology and a variety of Web 2.0 features is a wonderful interactive, immersive digital collection - but not a place-inclusive one. Unfortunately, while these findings were present during stage one, they were not able to be followed-up in stage two. A lack of confirmation across the two stages, and the complexity of this taxonomic issue, indicate an area for further research.

\section{Place $\neq$ geospatial technology}

Results also suggest there is no intrinsic link between place and geospatial technology. During stage one, this was demonstrated by collections that engage with a sense-of-place but perform this function without geospatial technology. The central Hawke's Bay Kete is a "digital knowledge basket of Central Hawke's Bay memories" (Central Hawke's Bay District Libraries, n.d., Home) and Akaroa Museum Collections reflect "the human history of the Banks Peninsula" (Akaroa Musuem, n.d., Collections). However, neither of these collections uses geospatial technology to perform these functions. Akaroa Museum Collections does not actually deploy any features associated with generating a sense-of-place (e.g. social interaction) identified above. It relies on rich visual representation instead. The stage two survey also indicates that place-inclusive digital collections do not necessarily employ geospatial technology. When asked to identify the geospatial features (if any) of their placeinclusive digital collections, 35\% of respondents answered "Do not use any digital maps or geospatial data". Despite the fact that maps and geospatial technology definitely add to the toolkit for engaging effectively with place, this finding is also strikingly positive from Roger Downs' perspective. It indicates that the end is not conflated with the means. To conceive of place is not just to conceive of the technology used to represent it (Downs, 1997, p.113) 


\subsection{Issues of Place}

It was anticipated that the issues surrounding this topic would be conceptual: issues would relate to how digital tools struggle to reflect social-bonds and the affective qualities of place. However, stage one results indicate that New Zealand's digital collections skilfully provide sense-of-place 'lens' using a wide-ranging digital toolkit. For stage two respondents, too, not many clashes between conceptual issues and digital technology stood out. Nonetheless, one respondent did state that:

many of our collection items are attached to more than one place. This lack of one-to-one correspondence made usability of the discovery interface one of the primary problems we had to solve.

This echoes theorists who cite 'locational uncertainty' as a significant problem when using "off-the-shelf GIS solutions" for cultural heritage purposes. It is difficult to relate places, as people are capable of understanding them, to collection content: "mapping can force us into unjustifiable certainty...and this isn't actually how most people think about the world" (GECO, 2012, Humphrey Southall, para.2). Te Papa Collections Online record for James Nairn's painting "Wellington Harbour" (Figure 13) uses a single pin to represent Wellington harbour, which Southall would consider too precise. However, the map's strict boundaries contrast neatly with a reproduction of the impressionist painting, a written explanation of Wellington Harbour as interpreted through "unmixed colours applied with the loose, flicking brushstrokes" and the painter's affinity for his subject since his primary interest was "the effects of light on the surface of the water" (Te Papa Tongarewa, n.d., Object: Wellington Harbour) Supplementing the Google Map's certainty with textual and visual representations, then, adds layers that are more consistent with human understanding (GECO, 2012, Humphrey Southall, para.2). 


\section{Figure 13: Item record for painting 'Wellington Harbour'}

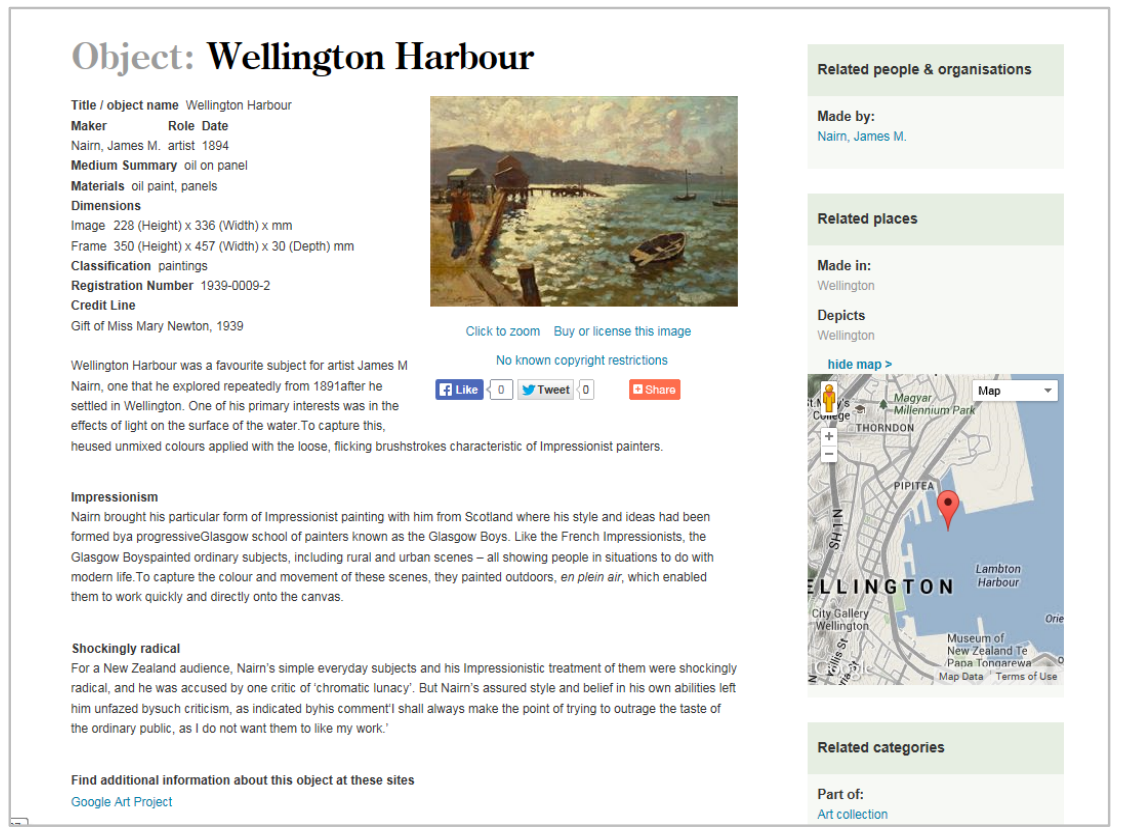

Generally, issues associated with place were far more 'real world' than conceptual mismatches. When asked to describe one particular issue that strongly impacted their placeinclusive digital collection, respondents reported issues thematically clustered around resourcing: "[d]ue to limited resources we haven't been able to make as wide a use of the tool as we would like" or "there is still more that could be done. This comes down to time and resourcing". The particular dimensions of resourcing that resonated strongly were time, staff capacity and IT: "[l]imitations on time and human resources" and "limited staff time" and "[t]ime, as well as server space/technical limitations". These three main resourcing issues were quite clearly interwoven. Still, the alternative to stretching limited staff also provided challenges. One respondent reported a significant challenge was standardising a project that relied on "volunteers, working from home, using any tools they liked".

Mostly, then, stage two responses were consistent with international case studies that reported mapping projects are difficult simply because they "take resources from other projects" (Harkema \& Nygren, 2012, para.19) or the biggest difficulty was integrating new technology into existing systems (Chen \& Notviett, 2010, p.167). This emphasis on resourcing issues as opposed to conceptual concerns shows that building a place-inclusive digital collection - with or without geospatial technology - faces no issues significantly 
dissimilar from other digital initiatives. Internationally, issues surrounding place-inclusive projects also tended "to align with problems with digital project implementation more generally" (Harkema \& Nygren, 2012, para.16).

Qualifying phrases like “we haven't been able to make as wide a use of the tool as we would like" and "there is still more that could be done" convey the sense of "uncertain incompleteness' around place-inclusive projects that survey respondents demonstrated. One respondent's project is "still a work in progress". Another respondent's final project seemed "unsatisfactory, but I am uncertain". This finding is problematic: it is hard to explain why respondents felt projects were incomplete when stage one digital collections all seem complete to the end-user. There is obviously scope for research into how users experience place-inclusive collections compared to those responsible for building them. Users are not aware that an organisation would "liked to have the full collection of digitised records accessible via a map, but due to time and space...have only selected a number of records". Having digital mapping tools newly at our disposal may provide one account of this uncertainty. One respondent noted there were "no resources set aside for mapping the collection, it's mostly seen as an extra rather than a must have". This is a telling comment, perhaps, indicating mapping tools are not an entrenched aspect of managing a digital collection yet and our cultural heritage sector is still very much learning. 


\section{Conclusion}

This project explored how New Zealand's cultural heritage organisations engage with and conceptualise place in a Web-based practice environment. Results firstly indicated that digital collections can seek to generate a sense-of-place. This approach refers to using a variety of features to mimic our subjective and experiential understanding of the world. Sense-of-place digital collections are engaging in an ontological activity: they seek to confer the status of place to a particular location. While theorists suggest that geospatial technology struggles to reflect this aspect of human understanding (Rumsey, 2009, p.6; GECO, 2012, Humphrey Southall, 2012, para. 2 - 3), results indicated geospatial technology is one tool within a cohort of digital technologies used to reflect the "activities, emotional linkages [and] social bonds" associated with place (Rumsey, 2009, p.6).

Results also showed that digital collections engage with place in its 'common-sense wrapper'. This approach refers to collections using the word place as a component of metadata or as an overarching thematic structure. In this case, the word place has multiple meanings or purposes, and refers to entities ranging considerably in scale. This approach highlights the difficulty of defining consistent qualities of place. Significantly, though, place is valuable precisely because of this flexibility: it can reflect various geographic constructs in a way that phrases like region, district and area cannot. This approach is also not mutually exclusive with the sense-of-place approach.

This study suggests that cultural heritage practitioners are very practice-oriented in their considerations of place. Firstly, place is seen to have most value in its capacity to be 'mapped' and deployed in support of innovative, meaningful, collection access. Secondly, the main issues associated with place-inclusive digital collections surround resourcing: staff time and technical difficulties. Significantly, practitioners cited issues associated with digital projects generally as effecting place-inclusive digital collections. This is rather than the anticipated conceptual or geospatially-specific issues.

The implications of this research are twofold. Firstly, theorists identify a gap between place as a concept relevant to cultural heritage concerns, and place as represented by digital technology; this project filled a valuable gap by starting to sketch a nuanced portrait of how 
place is conceived, valued, represented and deployed in our digital collections. By not having a purely technical focus, this project added to the "body of sustained critical thinking about the meanings and implications of...transformations, challenges and possibilities posed" by digital technology in the cultural heritage sector (Cameron \& Kenedrine, 2007, p.3). The most significant addition this project makes is its reflection on what place means to cultural heritage organisations. We often deploy this term without considering its connotations; or considering its relationship to the technology so frequently - and ever increasingly - used to represent it.

Secondly, and more immediately, this project identified many shared practical issues. It identified where organisations may or may not need guidance as they seek to engage meaningfully with geospatial technology; and as they seek to provide spaces for users to engage meaningfully with digital content. Further reflection on the role of place in geographically-inflected cultural heritage practice would be significantly valuable both academically, and at the individual project level. Notable areas for future research are as follows:

- The common-sense origin of the term place hides its capacity to be slippery and imprecise. Practitioners or teams beginning work with geospatial technology and/or place may consider a) defining place and its role or functions in their particular project context; and b) reflecting on what digital strategies best capture or generate this. Deliberate scrutiny of place and/or geospatial technology, where relevant, on project-by-project basis is recommended.

- New Zealand's CHIs seem to conceive of place from a perspective mostly consistent with Tuan (1977) and Relph (1976). But it would be valuable to explore how our digital collections are also consistent with alternative constructions of place like Doreen Massey's "progressive concept of place" (1994, p.155). Arguably, many features identified above (e.g. an empirical link between 'place' and 'people' as thematic structuring devices in digital collections) are consistent with Massey's argument that:

what gives a place its specificity is not some long internalized history [cf. Tuan and Relph] but the fact that it is constructed out of a particular constellation of social 
relations, meeting and weaving together at a particular locus (Massey, 1994, p.154).

- Some stage one examples reveal the fuzzy definitional boundaries of what constitutes a 'place-inclusive digital collection' (e.g. Bulldog and the Battlecruiser). Further research into the relationship between Web 2.0 features identified as placeinclusive and digital collections that apparently do not encourage a place-specific understanding would help sketch the boundaries of this complex concept.

- Digital and geospatial technology includes some specific functions (e.g. usercontribution; social-interaction) that reflect an understanding of place most relevant to cultural heritage concerns. It would be valuable to formally consolidate or define these functions through research into the functional requirements for geospatial technology deployed in a cultural heritage context.

- This project focused on the relationship between place, digital technology and cultural heritage concerns. However, results indicated that place has evidential value also. Research into the value of place to recordkeeping concerns would add to the body of knowledge on the relationship between place and information management more generally.

O One survey respondent stated that mapping has value as

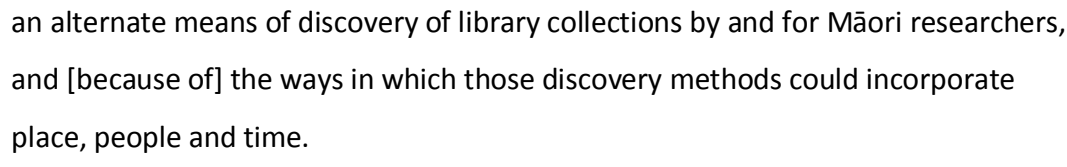

A very significant direction for future research is the role, value and function of geospatial technology and/or place within Te Ao Māori; and how these concepts reflect Te Ao Māori. 


\section{Works Cited}

Akaroa Museum. (n.d.). Collections. Retrieved 20 January, 2014, from http://www.akaroamuseum.org.nz/collections.asp.

Archives New Zealand. (2009). The community archive. Retrieved September 1, 2013, from http://thecommunityarchive.org.nz/.

Auckland War Memorial Museum \& Torpedo Bay Navy Museum. (2013). The bulldog and the battlecruiser: The 1913 voyage of the HMS New Zealand. Retrieved 10 January, 2014, from http://www.hmsnewzealand.com/.

BatchGeo. (2014). Retrieved February 11, 2014, from http://batchgeo.com/.

Berg, B. (2009). Qualitative research methods for the social sciences. Boston: Allyn \& Bacon.

Boeije, H. (2010). Analysis in qualitative research. Los Angeles: Sage.

Bray, Paula. (2012). Bring a plate: The importance of building community into your digital projects [video file]. Paper presented at the National Digital Forum, 20-21 November 2012. Video posted to:

http://webcast.gigtv.com.au/Mediasite/Play/fd9b9c855d8e4a708017a8e8c313efdb $1 \mathrm{~d}$ ?catalog=0218e4a1-9070-4b7f-b051-54f1933da8e9.

Bryman, A. (2012). Social research methods (4 ${ }^{\text {th }}$ ed). New York: Oxford University Press.

Bryman, A. (2008). Social research methods ( $3^{\text {rd }}$ ed). New York: Oxford University Press.

Buckland, M. \& Lancaster, L. (2004). Combining place, time and topic: The electronic cultural atlas initiative. D-lib magazine, 10(5). Retrieved from:

http://www.dlib.org/dlib/may04/buckland/05buckland.html.

Cameron, F. \& Kenedrine, S. (2007). Theorizing digital cultural heritage: A critical discourse. Cambridge, Mass.: MIT Press.

CEISMIC Consortium. (2014a). UC CEISMIC Digital archive. Retrieved Feburary 5, 2014, from: http://www.ceismic.org.nz/. 
Central Hawke's Bay District Libraries. (n.d.). Central Hawke's Bay Kete. Retrieved 21 January, 2014, from http://ketechb.peoplesnetworknz.info/en/site.

Chen, W., \& Nottviett, T. (2010). Digital map application for historical photos. In G. Chowdhury, C. Khoo \& J. Hunter (Eds.) The Role of Digital Libraries in a Time of Global Change (pp. 158-167). Berlin: Springer-Verlag.

Christchurch Art Gallery. (n.d.). Collection online. Retrieved 12 January, 2014, from http://christchurchartgallery.org.nz/collection/.

Clough, P., Tang, J., Hall, M. \& Warner, A. (2011). Linking archival data to location: A case study at the UK National Archives. Aslib proceedings: New perspectives, 63(2), 127147.

Cosgrove, D. (Ed.). (1999). Mappings. London: Reaktion Books.

Couclelis, H. (1999). Space, time and geography. In P. Longley, M. Goodchild, D. Maguire \& D. Rhind (Eds.) Geographical information systems: Principles, techniques, applications, and management. New York: John Wiley (pp.29-38).

Crane, G. (2004). Georeferencing in historical collections. D-lib magazine, 10(5). Available from: http://www.dlib.org/dlib/may04/crane/05crane.html.

Creswell, J. (2009). Research design: Qualitative, quantitative and mixed methods approaches ( $3 r d$ ed). Thousand Oaks, CA: Sage Publications.

Creswell, J. (2014). Research design: Qualitative, quantitative and mixed methods approaches (4th ed). Thousand Oaks, CA: Sage Publications.

Cresswell, T. (2004). Place: A short introduction. Malden, Mass.: Blackwell.

Cresswell, T. (2008). Space and place (1977): Yi-Fu Tuan. In P. Hubbard, R. Kitchin \& G. Valentine (Eds.) Key texts in human geography. (pp.53-59). Thousand Oaks, CA: Sage Publications.

Daniels, S., DeLyser, D., Entrikin, J. \& Richardson, D. (2011). Envisioning landscapes, making worlds: Geography and the humanities. New York: Routledge. 
Deegan, M. \&Tanner. S. (2006). Key Issues in digital preservation. In M. Deegan \& S. Tanner (Eds.) Digital preservation (pp.1-31). London: Facet.

Dodsworth, E., \& Nicholson, A. (2012). Academic uses of Google Maps and Google Earth in a library setting. Information technology and libraries, 31(2), 102-117.

Downs, R. (1998). The geographic eye: Seeing through GIS? Transactions in GIS, 2(2), 111121.

Dwiggins, D. (2010). Putting the "where" in the archives: Internet mapping and archival records. Library student journal. Retrieved from: http://www.librarystudentjournal.org/index.php/Isj/article/view/112/275

Edwardes, A. \& Purves, R. (2007a). Eliciting Concepts of Place for Text-based Image Retrieval. Paper presented at Workshop on Geographic Information Retrieval (GIR'07), CIKM, 6-9 November 2007. doi:10.1145/1316948.1316953.

Edwardes, A. \& Purves, R. (2007b). A theoretical grounding for semantic descriptions of place. In J. Ware \& G. Taylor (Eds.) Web and wireless geographical information systems: $7^{\text {th }}$ International symposium, W2GIS, 2007 (pp.107-120). Berlin: SpringerVerlag.

Ethington, P. (2007). Placing the past: 'Groundwork' for a spatial theory of history. Rethinking history: The journal of theory and practice, 11(4), 465-493.

Farrelly, G. (2013, June 28). Putting locative technology in its sense of place. [Web log post]. Retrieved from http://glenfarrelly.blogspot.co.nz/2013/06/putting-locativetechnology-in-its.html.

Florance, P. (2006). GIS collection development within an academic library. Library trends, $56(2), 222-235$.

Geospatial Engagement and Community Outreach [GECO]. (2012, March 7). Liveblog: Geospatial in the cultural heritage domain, past, present \& future. [Web log post]. Retrieved from: http://geco.blogs.edina.ac.uk/2012/03/07/liveblog-geospatial-inthe-cultural-heritage-domain-past-present-future/. 
Goodchild, M. \& Janelle D. (2010). Towards critical spatial thinking in the social sciences and humanities. GeoJournal, 75(1), 3-13. doi: 10.1007/s10708-010-9340-3.

Gregory, I. \& Ell. P. (2007). Historical GIS: Technologies, methodologies and scholarship. New York: Cambridge University Press.

Herring, S. (2010). Web-content analysis: Expanding the paradigm. In J. Hunsinger, L. Klastrup \& M. Allen (Eds.) The international handbook of internet research. (pp.223249). Berlin: Springer-Verlag.

Harkema, C. \& Nygren, C. (2012). Historypin for library image collections: New modes of access for unique materials at the University of Saskatchewan library. The Canadian journal of library and information practice and research, 7(2). Retrieved from: https://journal.lib.uoguelph.ca/index.php/peri/article/view/1970.

Historypin. (2013). Retrieved 17 May 2013, from: www.historypin.org.

Human ethics policy. (n.d.). Retrieved 03 February, 2014, from http://www.victoria.ac.nz/documents/policy/research-policy/human-ethicspolicy.pdf.

Human ethics guidelines. (n.d.). Retrieved 03 February, 2014, from http://www.victoria.ac.nz/documents/policy/research-policy/appendix-a-humanethics-committee-guidelines.pdf.

Jordan, T., Raubal, M., Gartell, B. \& Egenhofer, M. (1998). An affordance-based model of place in GIS. In T. Poiker \& N. Chrisman (Eds.) Eighth international symposium on spatial data handling (pp 98-109). Vancouver: International geographical union.

Knowles, A. (2008). Placing history: How maps, spatial data, and GIS are changing historical scholarship. New York: ERSI.

Lake, R., \& Farley, J. (2007). Infrastructure for the geospatial web. In A. Scharl \& K. Tochtermann (Eds.) The geospatial web: How geobrowsers, social software and the web 2.0 are shaping the network society (pp.15-26). London: Springer-Verlag. 
Leedy, P. D. and Ormrod, J. E. (2012). Practical research: Planning and design (10th ed.). USA: Pearson Education.

Library and Information Association of New Zealand [LIANZA]. (2012). Public library statistics 2011/2012. Retrieved 30 August, 2013 from http://www.lianza.org.nz/resources/lianza-publications/public-librarystatistics/public-library-statistics-20112012.

Massey, D. (1994). A global sense of place. In Space, place and gender (pp.146-155). Cambridge: Polity Press.

Ministry for Culture and Heritage. (n.d.). $28^{\text {th }}$ Māori Battalion. Retrieved 11 January, 2014, from http://www.28maoribattalion.org.nz/.

Ministry for Culture and Heritage. (2011). Quakestories Retrieved 13 February, 2014, from http://www.quakestories.govt.nz/.

Morris, S. (2006). Geospatial Web services and geoarchiving: new opportunities and challenges in geographic information services. Library trends, 55(2), 285-303.

National Services Te Paerangi. (n.d.) NZMuseums. Retrieved 11 September 2013, from http://www.nzmuseums.co.nz/about-us.

Neatline. (n.d.).Retrieved 14 May, 2013, from www.neatline.org.

OpenStreetMap. (n.d.) Retrieved 11 February, 2014, from http://www.openstreetmap.org.

Pickard, A. (2007). Research methods in information. London: Facet.

Nelson City Library, Tasman District Library, Marlborough District Library, Nelson Marlborough Institute of Technology, \& The Nelson Provincial Museum. (n.d.). The Prow. Retrieved 05 January, 2014, from http://www.theprow.org.nz/.

Relph, E. (1976). Place and placelessness. London: Pion Limited.

Ruecker, S., Radzikowska, M. \& Sinclar, S. (2011). Visual interface design for digital cultural heritage: A guide to rich-prospect-browsing. Farnham, England: Ashgate. 
Rumsey, A. (2009). Scholarly communication institute 7: Spatial technology and the humanities. Retrieved from http://www.uvasci.org/wpcontent/uploads/2009/10/sci7-published-full1.pdf.

Saldaña, J. (2009). The coding manual for qualitative researchers. Thousand Oaks, CA: Sage Publications.

Scharl, A. (2007). Towards the geospatial web: Media platforms for managing geotagged knowledge repositories. In A. Scharl\& K. Tochtermann (Eds.) The geospatial web: How geobrowsers, social software and the web 2.0 are shaping the network society (pp.3-14). London: Springer-Verlag.

Seamon, D. \& Sowers, J. (2008). Place and placelessness (1976): Edward Relph. In P. Hubbard, R. Kitchin \& G. Valentine (Eds.) Key texts in human geography. (pp. 43-51). Thousand Oaks, CA: Sage Publications.

Shawa, T. (2006). Building a system to disseminate digital map and geospatial data online. Library trends, 22(2), 254-263.

Southall, H. \&Pridal P. (2012). Old maps online: Enabling global access to historical mapping. E-Perimetron, $7(2), 73-81$.

Te Papa Tongarewa. (n.d.). Collections online. Retrieved 13 January, 2014, from http://collections.tepapa.govt.nz/.

Tuan, Y-F. (1977). Space and place: The perspective of experience. Minneapolis, MN: University of Minnesota Press.

Von Seggern, M., Merrill, A. \& Zhu, L. (2010). "Sense of place" in digital collections. International digital library perspectives, 26(4), 273-282. doi: $10.1108 / 10650751011087639$.

Voss, J. (2012, August 9). Jon Voss, Society of American Archivists 2012 Keynote [video file]. Video posted to http://www.youtube.com/watch?v=gyR59nFFMRg.

Upper Hutt City Library. (2013). RECOLLECT. Retrieved 12 January 2014, from: http://uhcl.recollect.co.nz/. 
Warf, B., \& Arias, S. (2009). The spatial turn: Interdisciplinary perspectives. New York: Routledge.

Weare, C., \& Lin, W. (2000). Content analysis of the World Wide Web: Opportunities and challenges. Social science computer review, 18(3), p. 272-292. doi: 10.1177/089443930001800304.

Withers, C. (2009). Place and the 'Spatial Turn' in geography and history. Journal of the history of ideas, 70(4), 637-658.

Flora Feltham

300091713

Word Count: 13,132 


\section{Appendix 1: Glossary}

Gecoding: the process "of finding associated geographic coordinates (latitude and longitude) from other geographic data, such as street addresses, or zip codes" (Chen \& Nottviett, 2010, p.161)

Georectifying: a process whereby "maps are digitally imaged...[and] the digital map image is then georeferenced, which converts the digital image from a non-real-world co-ordinate system (image space) to a real-world coordinate system" (Florance, 2006, p.323)

Georeferencing: the general process of relating heritage information to geographic locations through place names and/or coordinates (Clough, Tang, Hall, \& Warner, 2011, p.127)

Google Maps API: an Application Programming Interface that provides access to Google's dataset "to facilitate building third-party online services on top of their platforms" (Scharl, 2007, p.5) 


\section{Appendix 2: Example of descriptive codebook}

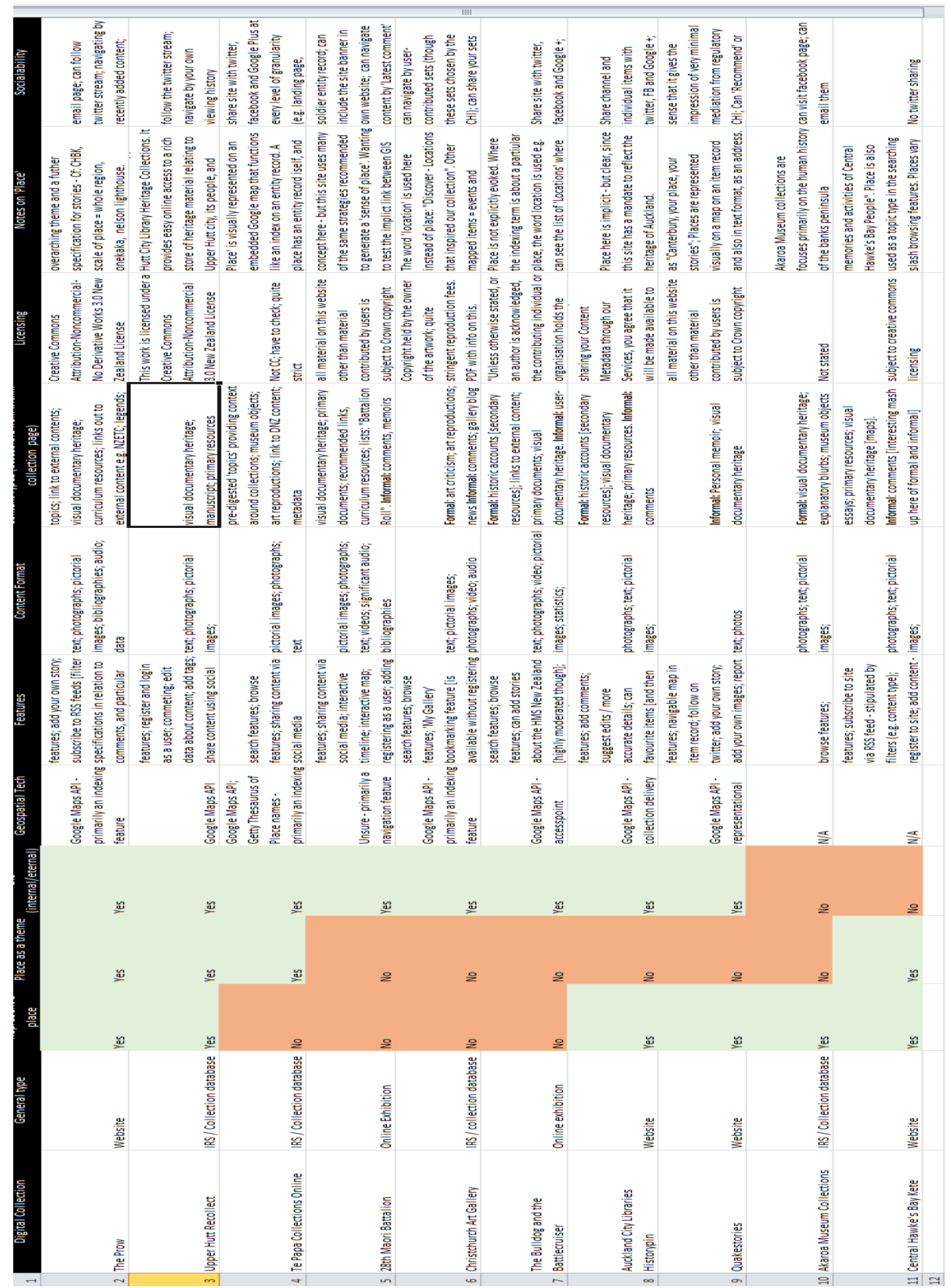




\section{Appendix 3: Example of survey}

\section{Email sent to NZLibs and NZR}

\section{Have you 'pinned' or 'mapped' your collection?}

Do your digital collections or projects focus on a particular region, city, neighbourhood or even local street?

\section{Can people explore your digital collection or website by 'Place'?}

If you answered 'yes' to any of these questions then I would be interested to hear from you.

I am a Masters student in Information Studies at Victoria University of Wellington. As a part of my degree I am conducting a research project looking at how the theme of 'place' is used to structure digital heritage collections and how (if at all) we use map-making tools, GIS and/or any digital mapping processes to represent 'place'.

I am seeking participation in an anonymous web survey by cultural heritage practitioners who have worked on digital projects or with digital collections that have any of the following characteristics:

- They use 'places' or 'place' as a category or categorising theme

- They use digital maps or geospatial technology/tools to support collection navigation or delivery

- They focus explicitly on the history and/or heritage of a particular location e.g. town, region, neighbourhood

This survey is entirely anonymous. All answers will be aggregated for data analysis and no identifying information will be recorded, so neither you nor the organisation you work for will be identifiable in any way. The survey contains 19 questions and should take no longer than 15 minutes. Participation is voluntary and if you wish to participate, you can do so via this link:

http://vuw.qualtrics.com/SE/?SID=SV eQOdteotFoM7YMd

If you have any questions or would like to receive further information about the project, please contact me at felthaflor@myvuw.ac.nzor on 0274628085 or you may contact my supervisor Dr. Sydney J. Shep at sydney.shep@vuw.ac.nzor on 04-463-5784.

Many thanks for your valuable participation,

Flora Feltham

**apologies for cross-posting** 


\section{Participant Information Sheet}

\section{Research Project Title:}

Approaches to 'place': Exploring how New Zealand's digital collections conceptualise a social understanding of space.

\section{Researcher:}

Flora Feltham, School of Information Management, Victoria University of Wellington

\section{Description:}

This study looks at how the theme of 'place' is used in digital heritage collections and how the available digital map-making tools and geospatial technology impacts our ability to represent this.

This study seeks to identify the practical strategies commonly associated with conceptualising 'place' using digital technology; explore how these strategies are deployed within our digital collections; and identify any issues associated with effectively using digital mapping technologies. This will benefit the sector by increasing our understanding of how increasingly available digital mapping and geospatial tools impact cultural heritage institutions and practices in New Zealand. Victoria University requires, and has granted, approval from the School's Human Ethics Committee.

I am inviting participation in an anonymous online survey from practitioners who have experience working on digital heritage projects or collections that have any of the following characteristics:

- They use 'places' or 'place' as a general category or categorising theme

- They focus explicitly on the history and/or heritage of a particular location e.g. town, region, neighbourhood

- They use digital maps or geospatial technology/tools to support collection navigation or delivery

Participation is voluntary and if you wish to participate, please select the 'Continue to Survey' link at the bottom of this page. The survey contains maximum 19 questions and should take no longer than 15 minutes.

All answers will be aggregated for data analysis and no identifying information will be recorded so neither you nor the organisation you work for will be identified in any written report produced as a result of this research, including possible publication in academic conferences and journals.

All material collected will be kept confidential, and will be viewed only by myself and my supervisor Dr. Sydney J. Shep, Senior Lecturer. The thesis will be submitted for marking to the School of Information Management, and subsequently deposited in the University Library. All data collected from participants will be destroyed within 2 years after the completion of the project. 
A copy of the full research report and an abstract containing a summary will be available from the Victoria University of Wellington Research Archive in February 2014. If you would like to be emailed a summary of research results, please contact me on my email address below and I will you a summary around the same time.

If you have any questions or would like to receive further information about the project, please contact me at felthaflor@myvuw.ac.nz or on 0274628085 . Alternatively, you may contact my supervisor Dr. Sydney J. Shep at sydney.shep@vuw.ac.nz or on 04-463-5784.

Many thanks for your valuable participation,

Flora Feltham

\section{Survey questions}

For the purposes of this survey a 'digital collection/project' refers to any of the following:

A collection of digitised or born-digital heritage content available online

A heritage website containing cultural and/or historical stories and images

An interactive database that provides access to heritage content online

An online exhibition containing curated digital heritage content

A digital history project accessible through a website

\section{A note on 'place':}

This study explores how 'place' is used as a theme in digital heritage collections/projects; and the ways digital maps, data, mapping services and tools impact how we represent places.

There is no strict definition of 'place' as an analytical concept, so please answer this survey in a way that just best fits with your perceptions of what makes somewhere a 'place'. That is, what makes somewhere a "meaningful location" (Cresswell, 2004) 
Which categories best describe your organisation?

Please select all that apply.
Archive
Art gallery
$\square$ Central government department
$\square$ Local government department
Museum
$\square$ Public library
Research library
$\square$ Other

Generally, would you describe your organisation's heritage activities as:
Locally focused
Regionally focused
Nationally focused
Other

Please think of any digital collections/projects that you been or are involved with. Many of these may engage with place.

In your experience, do any [please select all that apply]:
Use 'place' as a categorising or indexing theme alongside other themes like 'people'.
Use a particular place as the main thematic focus of the digital collection/project
Use mapping tools and/or geospatial data to represent places on a digital map
Clearly engage with place in any other way: 
Are these digital collections/projects primarily:

Created and maintained by your cultural heritage organisation alone

Created and maintained as collaborative projects with other cultural hertiage organisations

Other

What kinds of places do your digital collections/projets seek to capture?

Please select all that apply.

Places where content was produced

Places that content depcits visually

Places where events happened

Places mentioned in stories or memoirs

Places where content creators come from

Other

Can you please elaborate on why you selected these places?

Do your digital collections/projects include any of the following features that use digital maps and/or geospatial data (e.g. co-ordinates)?

Please select all that apply.

Geo-referenced historic maps

$\square$ Geo-tagged items 'pinned' on a digital map

Geo-tagged items 'pinned' on a 3D streetview

Text documents where place names and other geographic information has been tagged or enhanced (e.g. marked-up)

Geospatial data about collection available through an API

Any other features employing digital maps or geospatial data

Do not use any digital maps and/or geospatial data 
What do you think is the MAIN function of these features that use digital maps and/or geospatial data (e.g. co-ordinates) in your digital collections/projects?

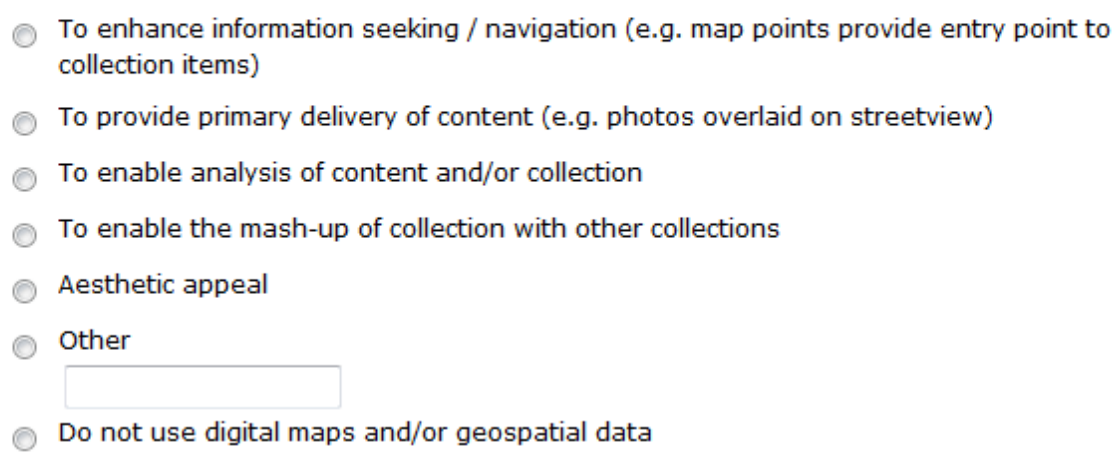

Do your digital collections/projects use any of the following mapping tools or services? Please select all that apply.

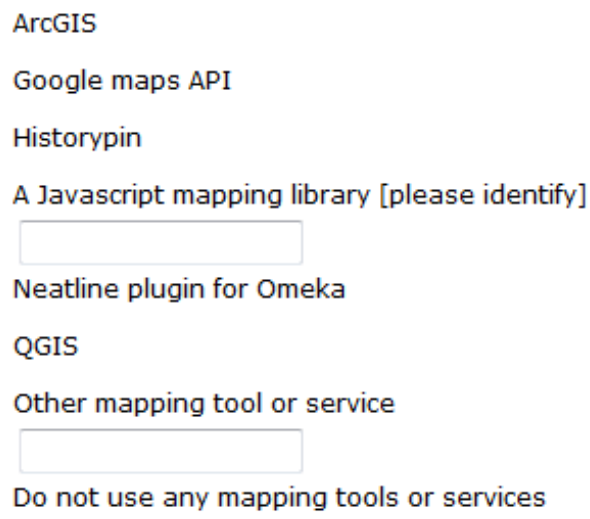

If applicable, what motivated the use of mapping tools in your digital collection/project? 
What features were you aiming to 'map'?

Please select all that apply.

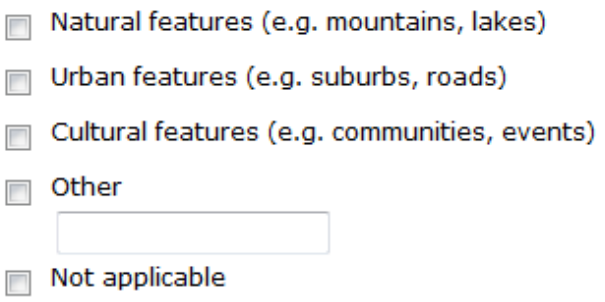

If applicable, what value do you think 'mapping' has added to your digital collection/project?

Have you achieved what you set out to achieve using mapping tools and technology in your digital collection/project? Were you:
Very successful
Successful
(1) Neutral
Somewhat unsuccessful
Very unsuccessful
Not applicable

If applicable, can you please elaborate about why you think this might be? 
Please think back on the development and creation of your digital collections/projects that engage with place.

How would you rate the simplicity of the following factors?

\begin{tabular}{|c|c|c|c|c|c|c|}
\hline & $\begin{array}{l}\text { Very } \\
\text { easy }\end{array}$ & Easy & Neutral & Difficult & $\begin{array}{l}\text { Very } \\
\text { difficult }\end{array}$ & $\begin{array}{l}\text { Not } \\
\text { applicable }\end{array}$ \\
\hline $\begin{array}{l}\text { Preparing and processing content for inclusion in } \\
\text { digital collection/project }\end{array}$ & ○ & $\bigcirc$ & $\bigcirc$ & ○ & ○ & ○ \\
\hline $\begin{array}{l}\text { Identifying appropriate mapping tools and services } \\
\text { for your collection/project }\end{array}$ & $\bigcirc$ & $\bigcirc$ & ○ & ○ & $\bigcirc$ & ○ \\
\hline $\begin{array}{l}\text { Learning how to use particular mapping tools and } \\
\text { services (e.g. Google maps) }\end{array}$ & $\bigcirc$ & $\bigcirc$ & ○ & $\bigcirc$ & ○ & ○ \\
\hline $\begin{array}{l}\text { Understanding geospatial data, metadata and } \\
\text { standards (e.g. co-ordinate systems, map } \\
\text { projections) }\end{array}$ & $\bigcirc$ & $\bigcirc$ & $\bigcirc$ & $\bigcirc$ & O & 0 \\
\hline Dedicating time to building digital collection/project & $\bigcirc$ & $\bigcirc$ & $\bigcirc$ & $\bigcirc$ & $\bigcirc$ & ○ \\
\hline $\begin{array}{l}\text { Dedicating funding to building digital } \\
\text { collection/project }\end{array}$ & ○ & $\bigcirc$ & O & ○ & 0 & ○ \\
\hline Dedicating staff to building digital collection/project & ○ & $\bigcirc$ & $\bigcirc$ & $\bigcirc$ & $\bigcirc$ & $\bigcirc$ \\
\hline Navigating technical or IT difficulties & O & ○ & ○ & O & O & O \\
\hline
\end{tabular}

Please describe a unique or particular issue that strongly impacted the process of building your digital collection/project that engages with place?

In your digital collections/projects that engage with place, please indicate the types of digitised and born-digital media they provide access to.

Please select all that apply.
Audio
Datasets
Maps
Non-photographic images
Photos
Text-based content
Other 
In your digital collections/projects that engage with place, please indicate the types of information included.

Please select all that apply.
Bibliographies
$\square$ Current events and news
$\square$ Cirriculum guides
Essays
$\square$ Facts lists
Government documents
$\square$ Historical accounts
$\square$ Historical newspapers
Interviews
$\square$ Links to other relevant websites
Literature
Myths and legends
Personal stories and memoirs
$\square$ Other

In your digital collections/projects that engage with place, is any of the following functionality included?

Please select all that apply.

Users can share content using social media

$\square$ Users can 'tag' content

$\square$ Users can add original content

$\square$ Users can add comments

$\square$ Users can register with and log in to collection/project

$\square$ Users can bookmark content or make 'sets' of items privately

$\square$ Users can download content for re-use

Other features for user contribution:

None of the above 
In your collections/projects that engage with place, are any of the following search and/or browse features included?

Please select all that apply.

Single search box for keyword searching

'Advanced' search feature

Links to 'Related' items or content

Tabbed pages

Faceted searching

An interactive map

An interactive timeline

'Recently Added' content lists

Other search and/or browse features

Given your experiences, how strongly do you agree with the following statements?

\begin{tabular}{|c|c|c|c|c|c|}
\hline & $\begin{array}{l}\text { Strongly } \\
\text { Agree }\end{array}$ & Agree & Neutral & Disagree & $\begin{array}{l}\text { Strongly } \\
\text { Disagree }\end{array}$ \\
\hline $\begin{array}{l}\text { Maps offer an intuitive way of navigating a } \\
\text { collection }\end{array}$ & O & O & O & O & O \\
\hline Communities attach histories to locations & ○ & O & 0 & $\odot$ & 0 \\
\hline $\begin{array}{l}\text { Heritage material usually has some } \\
\text { geographic component }\end{array}$ & 0 & ○ & ○ & O & ○ \\
\hline $\begin{array}{l}\text { People understand their world through } \\
\text { concepts like "home" }\end{array}$ & 0 & ○ & ○ & 0 & 0 \\
\hline $\begin{array}{l}\text { Modelling geographic relationships } \\
\text { generates new questions about content }\end{array}$ & O & ○ & O & O & O \\
\hline $\begin{array}{l}\text { Scholarly inquiry usually includes some } \\
\text { geographical considerations }\end{array}$ & (0) & ○ & O & 0 & O \\
\hline $\begin{array}{l}\text { Mapping practices enable collaboration and } \\
\text { mash-ups }\end{array}$ & O & ○ & 0 & O & 0 \\
\hline $\begin{array}{l}\text { Individuals attach histories to particular } \\
\text { locations }\end{array}$ & ○ & ○ & ○ & ○ & ○ \\
\hline
\end{tabular}

Given your experiences, what do you think is the BEST definition of 'place'? (From Agnew, 1987)

Places are the "the grid references we attach to portions of the earth's surface by...latitudinal and longitudinal positioning"

Places are the material and physical "settings for social relations or events"

Places are the locations to which people have "affective attachment" and social bonds through 


\section{Appendix 4: Example of qualitative analysis}

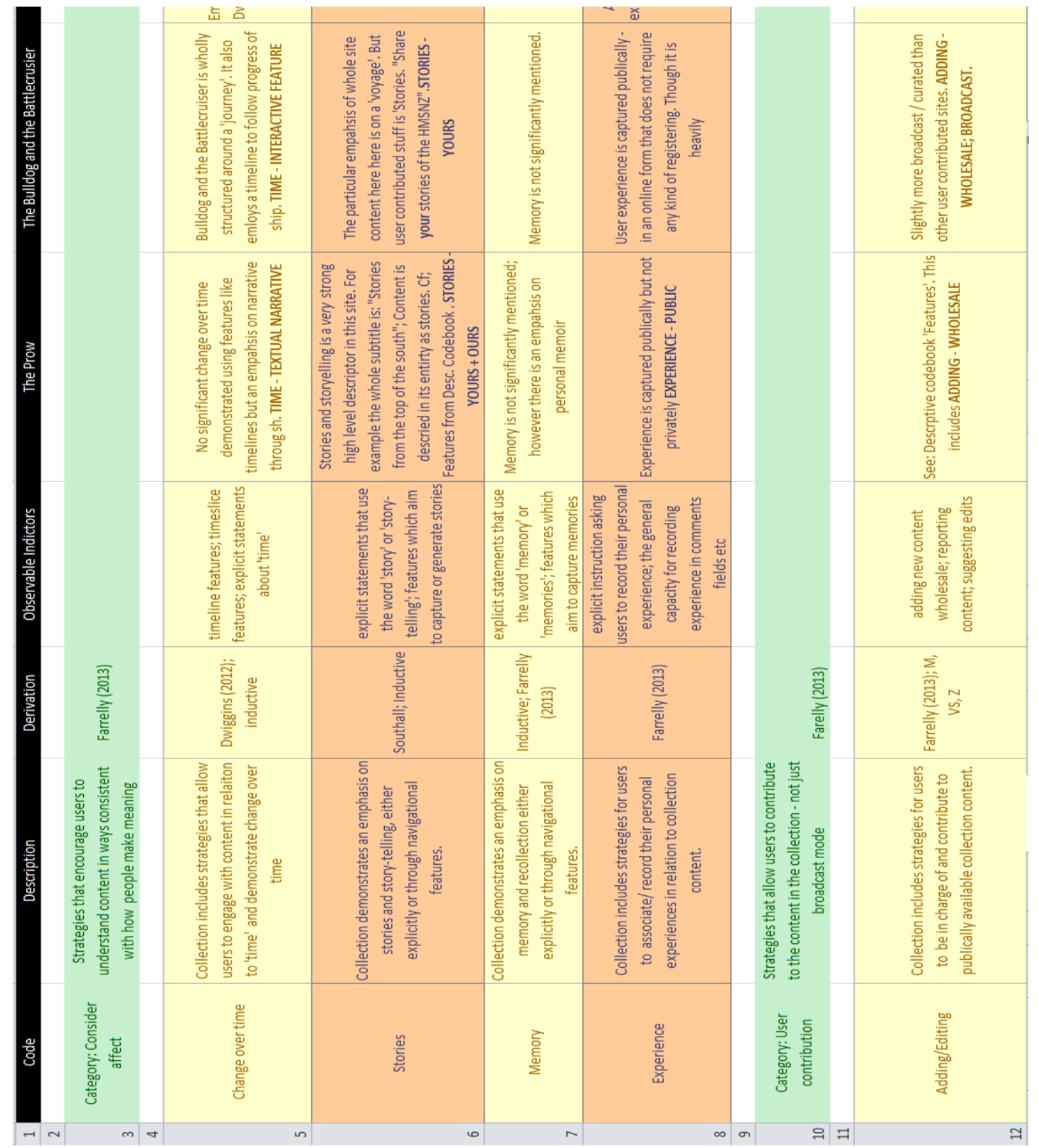




\section{Appendix 5: Example of quantitative analysis}

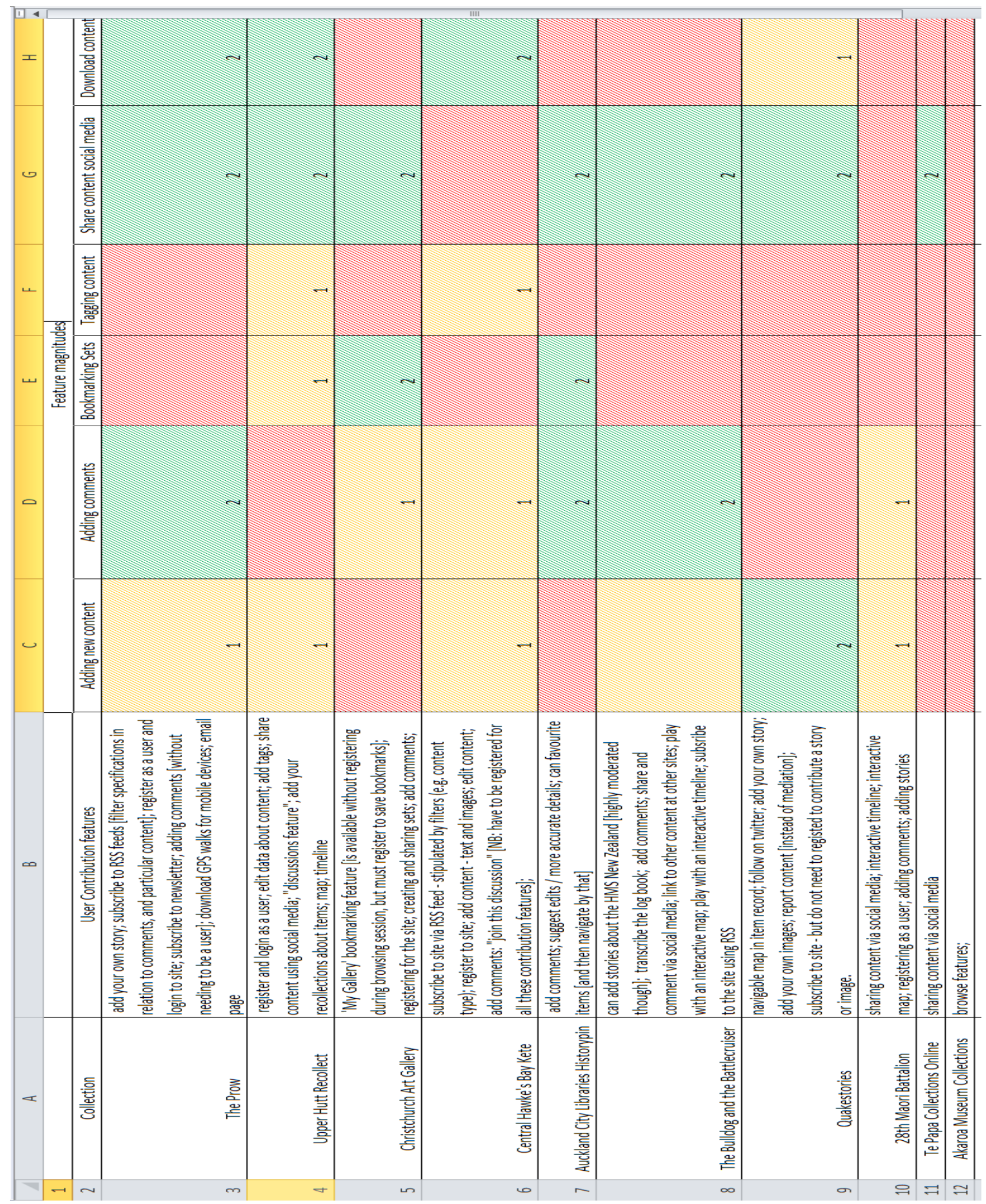

